\title{
The granite system near Betliar village (Gemeric Superunit, Western Carpathians): evolution of a composite silicic reservoir
}

\author{
Michal KUBIŠ1,2, Igor BROSKA ${ }^{1 *}$ \\ ${ }^{1}$ Geological Institute of the Slovak Academy of Sciences, Dúbravská cesta 9, P.O. Box 106, 84005 Bratislava, Slovakia; \\ igor.broska@savba.sk \\ 2 Present address: Geofos Ltd., Vel'ký diel 3323, 01008 Žilina, Slovakia \\ * Corresponding author
}

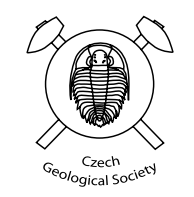

Boron- and fluorine-rich highly evolved granites in the Betliar area (Gemeric Unit, Western Carpathians) represent composite intrusion that formed probably during two distinct magmatic episodes. During the first stage, evolved granitic magma originating from an underlying volatile-rich reservoir intruded into an open fault system in the form of sill-like bodies and crystallized as equigranular or medium- to fine-grained rocks. The subsequent volatile flux enhanced postmagmatic alterations of the solidified granites and led to the formation of greisens with elevated amounts of tourmaline and $\mathrm{Nb}-\mathrm{Ta}-\mathrm{W}-\mathrm{Th}$ phases. During the second stage, magma from a deeper magmatic reservoir intruded as a mush containing $\mathrm{K}$-feldspar, albite, mica and quartz phenocrysts and gave rise to porphyritic granites. Partial dissolution and corrosion of the phenocrysts was enhanced by a pressure drop during emplacement of the porphyritic granites into middle-crustal level where the volatile-rich residual melt rapidly crystallized and is now preserved as quartz-albite-K-feldspar matrix with tourmaline and other accessories. Monazite and zircon geochronology indicates that the process occurred during Middle and Late Permian, and possibly extended to Early Triassic.

Keywords: porphyritic granite, tourmaline, apatite, volatiles, greisen Received: 21 May 2010; accepted: 6 July 2010; handling editor: D. Dolejš

\section{Introduction}

Prominent examples of a composite granite system can be found in the Betliar area. The granite complex consists of porphyritic and fine-grained (leuco-) granite that crops out within Palaeozoic volcanosedimentary rocks overprinted by contact metamorphism (Bajaník et al. 1984). The granites intruded the Gemeric Superunit, which is the uppermost crustal-scale tectonic unit of Alpine age in the Central Western Carpathians (Plašienka et al. 1997). Owing to their ubiquitous $\mathrm{Sn}, \mathrm{Nb}$, Ta and $\mathrm{W}$ mineralization (Grecula 1995; Malachovský et al. 2000; Uher et al. 2001), the most fractionated granites at Betliar can be geochemically classified as evolved S-type granites (Uher and Broska 1996; Broska and Uher 2001). Three granite types may be distinguished: (i) coarse-grained and porphyritic biotite granite, (ii) medium-grained muscovite granite, forming lower parts of the intrusive bodies, and (iii) fine-grained muscovite granite, often greisenized, occurring in the upper parts (Ončáková 1954). Typical of the Betliar area is also the occurrence of granite porphyry described by Ončáková (1954), Kamenický and Kamenický (1955) and Varček (1959).

The first K-Ar radiometric data for the Betliar granite porphyry yielded an "apparent” Alpine age (Kantor 1957). Later, Kovach et al. (1986) determined Permian ages for the Betliar granite using the $\mathrm{Rb}-\mathrm{Sr}$ isochron method.
Recent single-grain zircon dating gave a concordant age of $246 \pm 5 \mathrm{Ma}$ that was interpreted as a minimum age of crystallization (Poller et al. 2002). Electron microprobe dating of monazite yielded $273 \pm 13 \mathrm{Ma}$ (Finger and Broska 1999), while the in situ U-Pb SHRIMP zircon dating gave an average age of $277.2 \pm 1.9 \mathrm{Ma}$ (Radvanec et al. 2009). In this study, we present new petrographic, mineralogical and geochemical data bearing on the evolution of the Betliar granitic suite and report new monazite and zircon geochronological data.

\section{Analytical methods}

Whole-rock analyses were performed in the ACME Laboratories (Vancouver, Canada) using the following analytical procedure: (i) crushing of rock samples weighting 3 to $10 \mathrm{~kg}$, (ii) sintering of a $0.2 \mathrm{~g}$ sample aliquot with sodium peroxide, (iii) dissolution of the sinter cake, separation and dissolution of REE hydroxide-bearing precipitate, (iv) analysis by ICP-MS method with internal standardization to correct for matrix and drift effects. Natural rocks and pure quartz reagent (blank) were used as reference standards. Boron in the rock samples (GK-6, GK-7) has been analyzed by optical emission spectroscopy (OES) at the Geological Institute of the Slovak Academy of Sciences, Bratislava. 


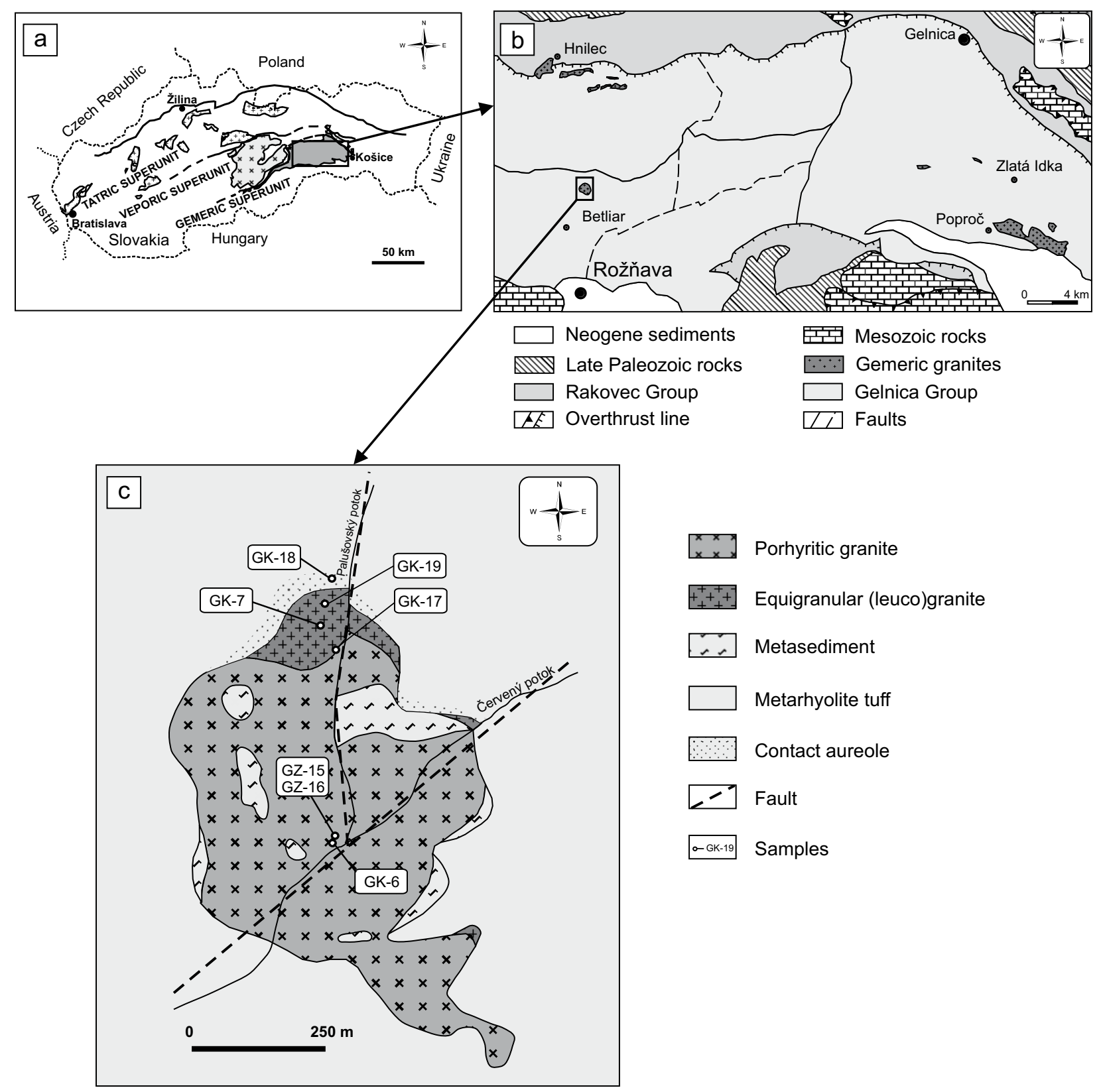

Fig. 1 Geological sketch map of the Betliar area. a - Position of the Gemeric unit in the Western Carpathians. b-The Gemeric unit with its granite occurrences; Betliar area shown by square (according to Bajaník et al. 1984). c - Sample locations in the Betliar granite body (after Rozložník et al. 1980).

Composition of rock-forming minerals was determined using a Cameca SX100 electron microprobe at the State Geological Survey (Bratislava, Slovakia) at the following conditions: accelerating voltage $15 \mathrm{kV}$, sample current $20 \mathrm{nA}$, beam diameter $5 \mu \mathrm{m}$ and calibration using natural standards. Apatite and monazite were analyzed using a Cameca SX50 electron microprobe at the Natural History Museum (London, United Kingdom). Operating conditions were: accelerating voltage $15 \mathrm{kV}$, beam current $25 \mathrm{nA}$, beam diameter 1 to $5 \mu \mathrm{m}$.

Monazite data acquired for geochronological considerations were obtained using the Cameca SX100 microprobe at the State Geological Survey (Bratislava, Slovakia) with the following operating conditions: accelerating voltage $15 \mathrm{kV}$, beam current $80-150 \mathrm{nA}$, counting time $75-130 \mathrm{~s}$ and beam diameter $5 \mu \mathrm{m}$. The following synthetic and natural standards were used for calibra- 

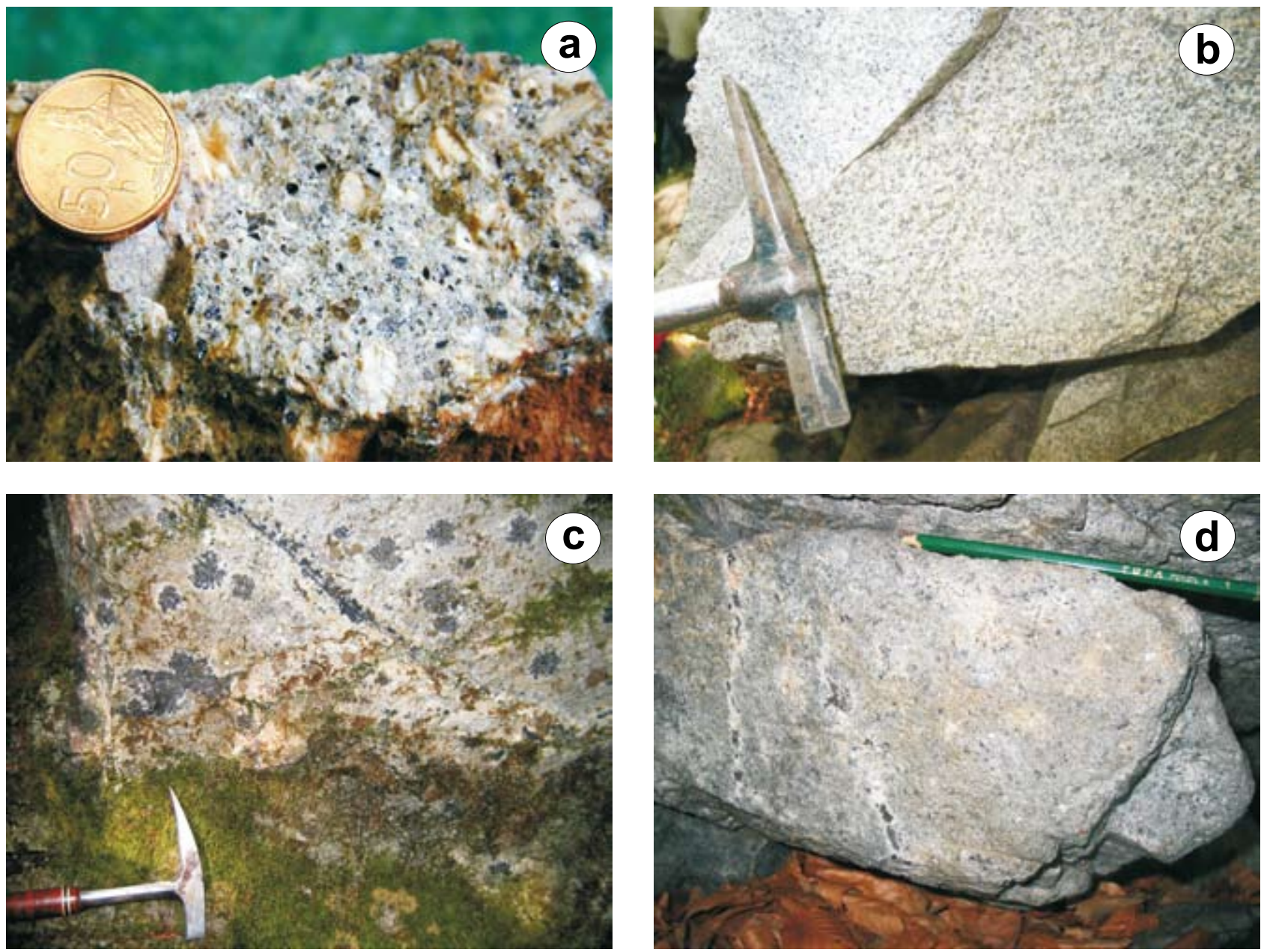

Fig. 2 Textures of the Betliar granitic rocks. a - Porphyritic granite ("granite porphyry"). b - Fine-grained (equigranular) granite. $\mathbf{c}-$ Mediumgrained granite with nodular tourmaline. $\mathbf{d}$ - Medium-grained granite with a quartz-tourmaline vein.

tion: $\mathrm{Al}-\mathrm{Al}_{2} \mathrm{O}_{3}, \mathrm{Si}$ - wollastonite, $\mathrm{P}$ - apatite, $\mathrm{Pb}-\mathrm{PbS}$, $\mathrm{U}-\mathrm{UO}_{2}, \mathrm{Th}-\mathrm{ThO}_{2}, \mathrm{REE}-(\mathrm{REE}) \mathrm{PO}_{4}$. Further analytical details pertaining to the monazite dating method can be found in Konečný et al. (2004).

Zircon was analyzed by LA-ICP-MS at the Institute of Geochemistry, Mineralogy and Mineral Resources, Charles University (Prague, Czech Republic). ${ }^{206} \mathrm{~Pb} /{ }^{238} \mathrm{U}$ and ${ }^{207} \mathrm{~Pb} /{ }^{206} \mathrm{~Pb}$ zircon ages were determined using a $213 \mathrm{~nm}$ Q-switched Nd-YAG NewWave Microprobe laser coupled to a multi-collector PlasmaQuad 3 ICP-MS. The laser beam with energy up to $2.5 \mathrm{~mJ} /$ pulse was directed through a series of apertures and microscope optics and focused onto the sample surface. Spot analyses covered diameter of $10-15 \mu \mathrm{m}$. The samples were placed in a quartz cell mounted on a computer-driven motorized stage. The ablated material from the cell was flushed out by a stream of $\mathrm{He}$ gas. The $\mathrm{U}-\mathrm{Pb}$ ages were recalculated using the Isoplot/ Ex program - version 2.49 (Ludwig 2001); all the age data in the text are given at the $2 \sigma$ confidence level.

\section{The Betliar granite body}

The Betliar granite forms an irregular intrusive body $(600 \mathrm{~m}$ in diameter at the present surface level) situated $3.6 \mathrm{~km} \mathrm{~N}$ of the Betliar village (Fig. 1). The granite body intruded Lower Palaeozoic metasediments, the "porphyroid series" of the Gelnica Group (Bajaník et al. 1984) that is composed of metavolcanic rocks and phyllites. The cliffs in the vicinity of Betliar mainly consist of porphyritic granite (Fig. 2a) and, to a lesser extent, of finegrained (leuco-) granite, which crops out in the northern part of the intrusion (Fig. 2b). Direct contact between the two granite types could not have been observed. The medium- to coarse-grained granite occurs in the form of large blocks, up to several meters in size, situated within both the porphyritic and fine-grained (leuco-) granite. The contact between granites and surrounding metasediments is sharp. Medium- to fine-grained granites locally show abundant tourmaline-rich nodular aggregates (Fig. 2c). 

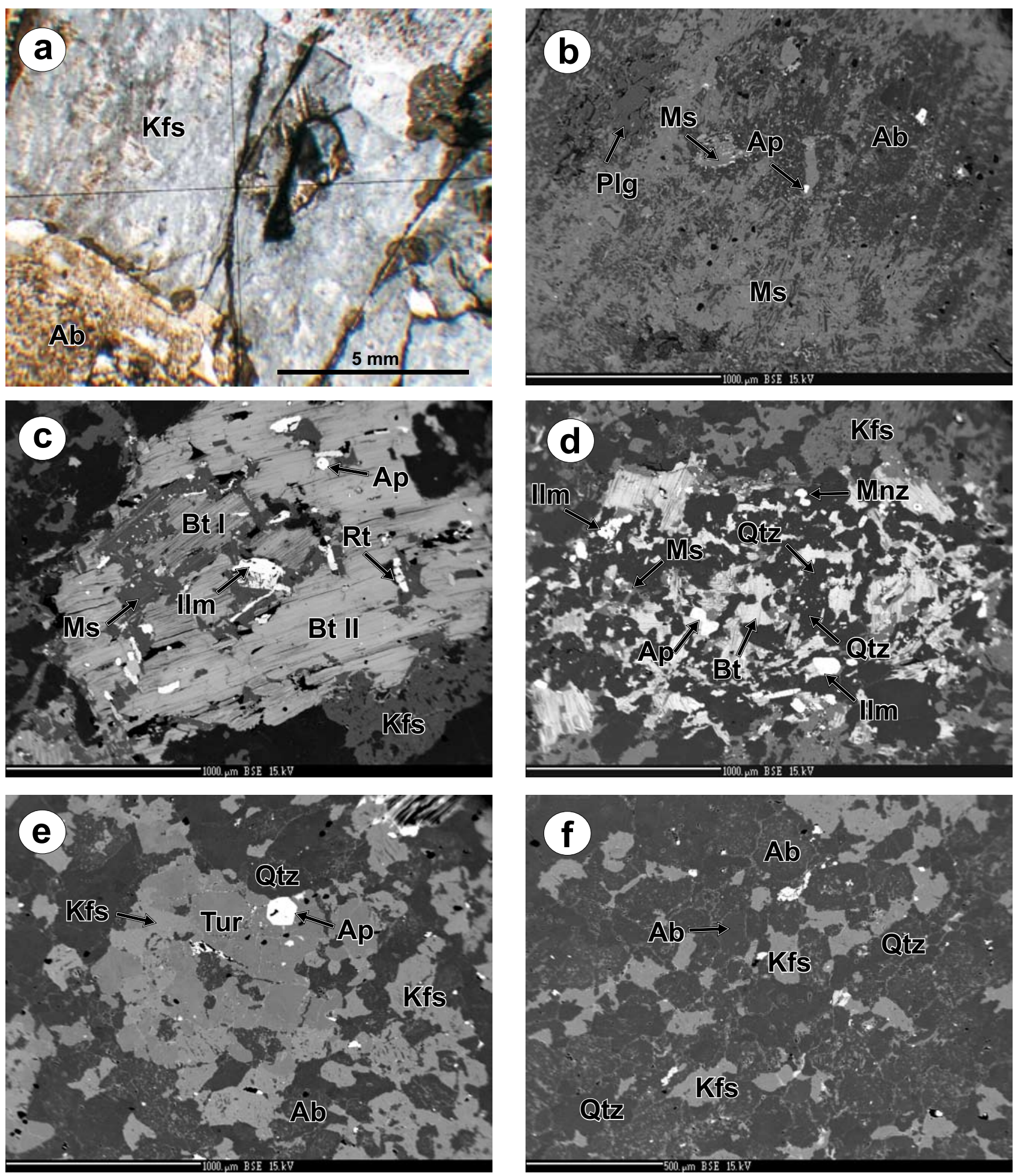

Fig. 3 Photomicrographs and backscattered electron images from the porphyritic granite ("granite porphyry") - sample GK-6. a - K-feldspar phenocryst in porphyritic granite. $\mathbf{b}$ - Albite phenocryst mainly altered to sericite. $\mathbf{c}$ - Two generations of biotite. $\mathbf{d}$ - Secondary paragenesis on former mineral (cordierite?). $\mathbf{e}$ - Granitic matrix enriched in tourmaline. f - Granitic matrix composed of albite, K-feldspar and quartz.

Metarhyolite tuffs surrounding the fine-grained (leuco-) granite have been strongly altered and were crosscut by numerous quartz veinlets. Post-magmatic alteration, particularly greisenization, is developed to a limited extent only and confined to the contact of the fine-grained granite with the host rocks. The granites, however, were 
crosscut by quartz and quartz-tourmaline veinlets (Fig. 2d).

\subsection{The porphyritic granite}

The porphyritic granite (samples: GK-6, GZ-15, GZ-16) contains megacrysts of alkali feldspar (1-4 cm in size) and quartz $(0.5-3 \mathrm{~cm})$ that are disseminated in a medium- to fine-grained matrix (Fig. 3a). Their groundmass essentially consists of equigranular K-feldspar, albite and quartz in similar volumetric proportions, with smaller quantities of white mica and tourmaline.

Alkali feldspar forms subhedral to anhedral crystals, usually with perthitic structure (string, vein and patch perthite). Subhedral megacrysts (up to $0.5 \mathrm{~cm}$ ) and matrix albite $\left(\mathrm{An}_{00-07}\right)$ were strongly sericitized (Fig. 3b). The strongly altered plagioclase rarely shows relic cores $\left(\mathrm{An}_{30}\right)$. Quartz forms anhedral to subhedral grains showing partial magmatic resorption, which also affected plagioclase, and undulose extinction. Biotite occurs as subhedral plates, 0.3 to $1 \mathrm{~mm}$ in size, frequently clustered into aggregates (Fig. 3c). White mica forms mainly irregular grains, but isolated flakes occur as secondary alteration products in plagioclase (Fig. 3d). The rock matrix is composed of albite, K-feldspar, quartz and tourmaline (Fig. 3e-f). Typical accessory minerals include apatite, zircon, monazite, xenotime, ilmenite, rutile, thorite, pyrite and fluorite.

\subsection{Equigranular granite}

The fine-grained, equigranular granite (average grain size: 0.1-2.0 mm, Fig. 4a) consists of K-feldspar (25.7 vol. \%), quartz (42.2 vol. \%), albite (19.0 vol. \%) and white mica (13.1 vol. \%; Fig. 4b). K-feldspar with average size of 0.5 to $2 \mathrm{~mm}$ forms subhedral to euhedral grains, often with perthitic lamellae. Albite $\left(\mathrm{An}_{00-01}\right)$ shows randomly oriented, subhedral crystals (up to $1 \mathrm{~mm}$ in size), often strongly sericitized. White mica occurs as isolated flakes or interstitial aggregates (Fig. 4c). Quartz mostly forms anhedral to subhedral crystals (up to $2 \mathrm{~mm}$ ). The most common accessory minerals are tourmaline, apatite, zircon, fluorite, rare $\mathrm{Nb}$-Ta oxide, wolframite, scheelite and cheralite (samples GK-7 and GK-19). The granites were strongly altered to greisens and became enriched in apatite (Fig. 4d) and $\mathrm{Nb}-\mathrm{Ta}-\mathrm{W}-\mathrm{Th}$ phases such as columbite, thorite and ixioliote.

The medium-grained monzogranite (sample GK-17) is a grey or, locally, light grey rock that consists of quartz, alkali feldspar, albite and white mica; biotite is absent. Quartz forms small porphyritic anhedral grains (up to $1 \mathrm{~cm})$. Alkali feldspar occurs as subhedral to anhedral grains with chessboard twining. Albite $\left(\mathrm{An}_{01}\right)$ is subhedral and strongly sericitized. White mica is common and it forms irregular cluster aggregates. Accessory minerals include abundant tourmaline, zircon, apatite, monazite and thorite. Tourmaline occurs as spectacular clusters. Apatite is also abundant (Fig. 4e). In some places, granitic rock was cross-cut by quartz-tourmaline veins (Fig. 4f).

\section{Geochemistry}

The Betliar granites belong to typical S-type peraluminous granites (Tab. 1). The most widespread porphyritic granites (samples GK-6, GZ-15, 16) are strongly peraluminous (alumina saturation index, ASI $=1.2$ to 1.6 ), with high $\mathrm{SiO}_{2}$ contents ( 73 to $75 \mathrm{wt}$ \%), relatively high alkali concentrations, especially of $\mathrm{K}_{2} \mathrm{O}$ ( 3 to 5 wt. \%), low contents of $\mathrm{MgO}$ (0.3 to 0.9 wt.\%), $\mathrm{CaO}$ (0.3 to 0.4 wt.\%), $\mathrm{FeO}$ (1.25 to 1.75 wt.\%), $\mathrm{Sr}$ (13 to $33 \mathrm{ppm}$ ) and $\mathrm{Ba}(104$ to $246 \mathrm{ppm}$ ) (Fig. 5). The porphyritic granites contain approx. 0.15 wt. $\% \mathrm{P}_{2} \mathrm{O}_{5}, 300-420 \mathrm{ppm} \mathrm{Rb}, 10-12 \mathrm{ppm}$ $\mathrm{Nb}, \sim 2 \mathrm{ppm}$ Ta and are enriched in boron ( $\sim 375 \mathrm{ppm} \mathrm{B})$. The rare earth element patterns show pronounced negative europium anomalies $\left(\mathrm{Eu} / \mathrm{Eu}^{*}=0.22\right.$ to 0.31$)$ and low $\mathrm{La}_{\mathrm{N}} / \mathrm{Yb}_{\mathrm{N}}$ ratios (2.2 to 3.8) (Fig. 6).

The medium-grained granite (GK-17) has a more evolved composition with high $\mathrm{SiO}_{2}$ (74.7 wt. \%), low peraluminosity (ASI $=1.28)$ and high $\mathrm{Rb}(\sim 477 \mathrm{ppm}), \mathrm{Nb}(\sim 28 \mathrm{ppm})$, $\mathrm{Ta}(\sim 14 \mathrm{ppm})$ and $\mathrm{W}(\sim 24 \mathrm{ppm})$ contents. Low $\mathrm{CaO}(\sim 0.42$ wt. \%), Ba ( 130 ppm), REE and $\mathrm{Sr}(\sim 17 \mathrm{ppm})$ contents are characteristic of this granite type. Chondrite-normalized REE pattern is relatively flat $\left(\mathrm{La}_{\mathrm{N}} / \mathrm{Yb}_{\mathrm{N}}=1.3\right)$ with a distinct negative Eu anomaly $\left(\mathrm{Eu} / \mathrm{Eu}^{*}=0.19\right)$ (Fig. 6).

The more evolved equigranular fine-grained granites (GK-7, GK-19) located along the northern border of the Betliar intrusive complex are enriched in phosphorus (0.37 to 0.47 wt. $\% \mathrm{P}_{2} \mathrm{O}_{5}$ ) (Fig. 5). High Rb contents (553 to $697 \mathrm{ppm}$ ) and a strongly peraluminous nature (ASI = 1.4 to 2.4 ) reveal a highly differentiated magma whereas $\mathrm{Ba}(130-145 \mathrm{ppm})$ and $\mathrm{Sr}(12-25 \mathrm{ppm})$ concentrations are similar to those in the porphyritic and mediumgrained granites. A higher degree of fractionation is also demonstrated by increased concentrations of incompatible rare metals: $\mathrm{Nb}(47-73 \mathrm{ppm}), \mathrm{Ta}(14.3-18.2 \mathrm{ppm})$ and $\mathrm{W}$ (21-38 ppm). By contrast, Sn contents (13 to $30 \mathrm{ppm}$ ) are relatively low. The chondrite-normalized REE patterns are rather flat $\left(\mathrm{La}_{\mathrm{N}} / \mathrm{Yb}_{\mathrm{N}}=0.9\right.$ to 1.2) and show deep negative $\mathrm{Eu}$ anomalies $\left(\mathrm{Eu} / \mathrm{Eu}^{*}=0.20\right.$ to 0.30$)$.

\section{Rock-forming minerals}

\subsection{Alkali feldspars}

Alkali feldspars of the Betliar granite body are close to pure end-members. Albite concentrations in K-feldspar 

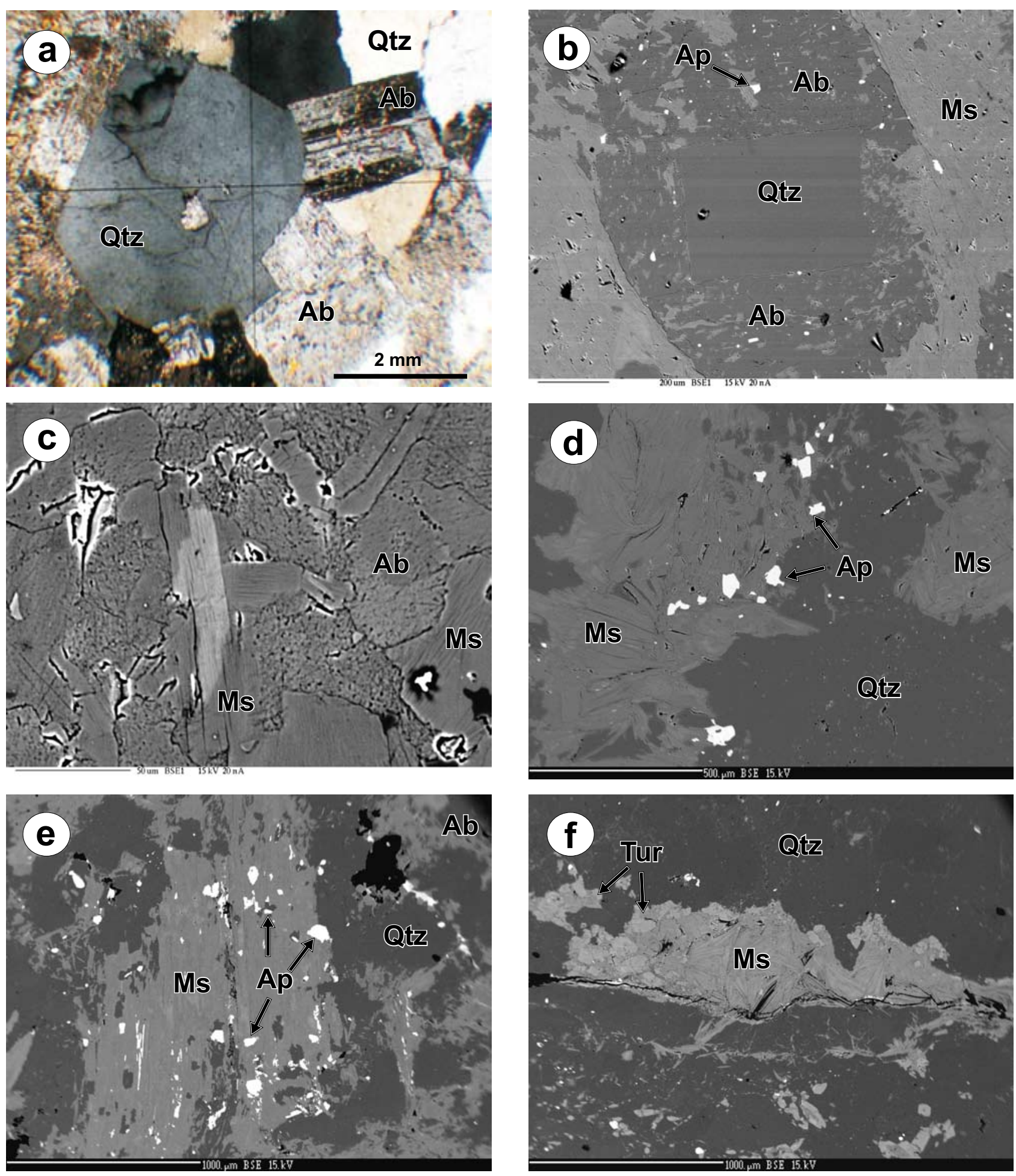

Fig. 4 Photomicrographs and backscattered electron images from equigranular and fine- to medium-grained granites. a - Texture of equigranular granite (sample GK-7). b - Equigranular matrix and euhedral quartz, albite and mica (GK-7). c - Matrix and metamorphic white mica, Fe-Al celadonite and Al-celadonite (GK-7). d - Greisenized equigranular granite with quartz mica and abundant apatite (GK-19). e - Granite with quartz, albite, white mica and abundant apatite (GK-17). f - Quartz-tourmaline vein with muscovite (GK-17).

do not exceed 4 mol. \% $\mathrm{Ab}$ and anorthite abundances in albite are below 3 mol. \% An (Tab. 2). Increased phosphorus contents were observed in K-feldspar and albite of the main granite types and they correlate with the high peraluminosity of the magma (ASI $=1.2-1.6$; Tab. 1) whereby $\mathrm{P}$ behaves as an incompatible element. 
Tab. 1 Major- and trace-element data for the granites from Betliar area. For locations see Fig. 1.

\begin{tabular}{|c|c|c|c|c|c|c|c|}
\hline \multirow{2}{*}{$\begin{array}{l}\text { Rock type } \\
\text { rock varieties }\end{array}$} & \multicolumn{3}{|c|}{ porphyritic granite } & \multicolumn{3}{|c|}{ equigranular granite } & \multirow[t]{2}{*}{ rhyolite metatuf } \\
\hline & & & & medium-grained & fine-grained & fine-grained & \\
\hline Sample & GZ-15 & GZ-16 & GK-6 & GK-17 & GK-7 & GK-19 & GK-18 \\
\hline $\mathrm{SiO}_{2}$ & 72.85 & 73.69 & 74.61 & 74.67 & 71.74 & 69.44 & 66.18 \\
\hline $\mathrm{TiO}_{2}$ & 0.21 & 0.10 & 0.22 & 0.07 & 0.06 & 0.05 & 0.48 \\
\hline $\mathrm{Al}_{2} \mathrm{O}_{3}$ & 14.89 & 13.69 & 13.24 & 13.88 & 16.47 & 18.60 & 14.56 \\
\hline $\mathrm{Fe}_{2} \mathrm{O}_{3}$ & 1.32 & 1.25 & 1.75 & 1.19 & 0.88 & 0.54 & 3.99 \\
\hline $\mathrm{MnO}$ & 0.02 & 0.03 & 0.03 & 0.02 & 0.02 & 0.01 & 0.11 \\
\hline $\mathrm{MgO}$ & 0.91 & 0.21 & 0.3 & 0.37 & 0.46 & 0.62 & 1.54 \\
\hline $\mathrm{CaO}$ & 0.26 & 0.27 & 0.42 & 0.42 & 0.66 & 0.52 & 4.58 \\
\hline $\mathrm{Na}_{2} \mathrm{O}$ & 3.41 & 3.29 & 3.11 & 3.49 & 3.7 & 0.16 & 3.20 \\
\hline $\mathrm{K}_{2} \mathrm{O}$ & 3.19 & 4.92 & 4.78 & 3.99 & 4.34 & 5.79 & 3.90 \\
\hline$\underline{\mathrm{P}_{2} \mathrm{O}_{5}}$ & 0.15 & 0.16 & 0.14 & 0.31 & 0.47 & 0.37 & 0.15 \\
\hline Total & 97.31 & 97.69 & 100.03 & 99.92 & 100.12 & 100.10 & 99.80 \\
\hline B & - & - & 372 & - & 170 & - & - \\
\hline $\mathrm{Ba}$ & 150 & 104 & 246 & 130 & 145 & 136 & 776 \\
\hline Cs & - & - & 12.1 & 10.0 & 12.1 & 7.5 & 9.4 \\
\hline Co & 6.0 & 7.0 & 1.3 & 2.4 & 0.7 & 1.5 & 3.9 \\
\hline $\mathrm{Ga}$ & - & 24.0 & 20.8 & 23.7 & 35.5 & 28.4 & 16.8 \\
\hline $\mathrm{Hf}$ & - & - & 3.8 & 2.6 & 2.3 & 3.6 & 5.3 \\
\hline $\mathrm{Nb}$ & 10.0 & 11.0 & 11.9 & 27.7 & 46.8 & 73.0 & 10.4 \\
\hline $\mathrm{Rb}$ & 300.0 & 420.0 & 339.7 & 476.5 & 696.5 & 553.4 & 137.8 \\
\hline $\mathrm{Sn}$ & - & 24.5 & 15.0 & 15.0 & 13.0 & 30.0 & 14.0 \\
\hline $\mathrm{Sr}$ & 13.0 & 17.0 & 32.6 & 16.8 & 24.5 & 12.7 & 170.2 \\
\hline $\mathrm{Ta}$ & - & 2.4 & 2.3 & 13.5 & 14.3 & 18.2 & 0.9 \\
\hline $\mathrm{Th}$ & 21.0 & 29.0 & 16.2 & 8.0 & 10.6 & 11.8 & 13.3 \\
\hline $\mathrm{U}$ & 4.0 & 3.0 & 3.5 & 3.4 & 3.9 & 4.1 & 2.6 \\
\hline W & - & - & 8.0 & 24.0 & 21.2 & 37.5 & 9.2 \\
\hline $\mathrm{Zr}$ & 133.0 & 76.0 & 114.0 & 46.9 & 34.4 & 48.4 & 170.3 \\
\hline Mo & - & - & $<0.2$ & $<0.1$ & 0.1 & $<0.1$ & $<0.1$ \\
\hline $\mathrm{Y}$ & 26.82 & 15.48 & 26.80 & 11.80 & 7.70 & 9.30 & 34.60 \\
\hline $\mathrm{La}$ & 13.33 & 6.51 & 17.20 & 2.60 & 1.80 & 1.30 & 32.60 \\
\hline $\mathrm{Ce}$ & 25.83 & 13.33 & 38.50 & 5.60 & 4.00 & 4.00 & 67.10 \\
\hline $\operatorname{Pr}$ & 3.68 & 1.88 & 4.50 & 0.82 & 0.63 & 0.62 & 8.50 \\
\hline $\mathrm{Nd}$ & 14.48 & 6.93 & 15.90 & 3.50 & 2.40 & 2.60 & 31.90 \\
\hline $\mathrm{Sm}$ & 3.86 & 2.04 & 3.90 & 0.98 & 1.10 & 1.14 & 6.29 \\
\hline $\mathrm{Eu}$ & 0.30 & 0.10 & 0.38 & 0.07 & 0.12 & 0.09 & 1.16 \\
\hline $\mathrm{Gd}$ & 4.46 & 2.03 & 3.57 & 1.35 & 1.34 & 1.58 & 4.74 \\
\hline $\mathrm{Tb}$ & 0.79 & 0.43 & 0.77 & 0.35 & 0.28 & 0.36 & 0.95 \\
\hline Dy & 5.22 & 3.02 & 4.23 & 2.16 & 1.55 & 1.87 & 5.65 \\
\hline Ho & 0.99 & 0.59 & 0.86 & 0.40 & 0.28 & 0.30 & 1.19 \\
\hline $\mathrm{Er}$ & 2.88 & 1.85 & 2.57 & 1.22 & 0.68 & 0.86 & 3.17 \\
\hline $\mathrm{Tm}$ & 0.45 & 0.31 & 0.40 & 0.21 & 0.15 & 0.15 & 0.53 \\
\hline $\mathrm{Yb}$ & 2.99 & 2.04 & 3.02 & 1.31 & 1.00 & 1.00 & 2.90 \\
\hline $\mathrm{Lu}$ & 0.43 & 0.29 & 0.38 & 0.22 & 0.11 & 0.13 & 0.47 \\
\hline ASI & 1.56 & 1.22 & 1.20 & 1.28 & 1.37 & & \\
\hline $\mathrm{Eu} / \mathrm{Eu}^{*}$ & 0.22 & 0.15 & 0.31 & 0.19 & 0.30 & 0.20 & 0.65 \\
\hline Ts $[\mathrm{Zr}]$ & 806 & 741 & 773 & 708 & 686 & 744 & \\
\hline
\end{tabular}

Ts $[\mathrm{Zr}]$ zircon saturation temperatures calculated after Watson and Harrison $(1983)\left({ }^{\circ} \mathrm{C}\right)$ 

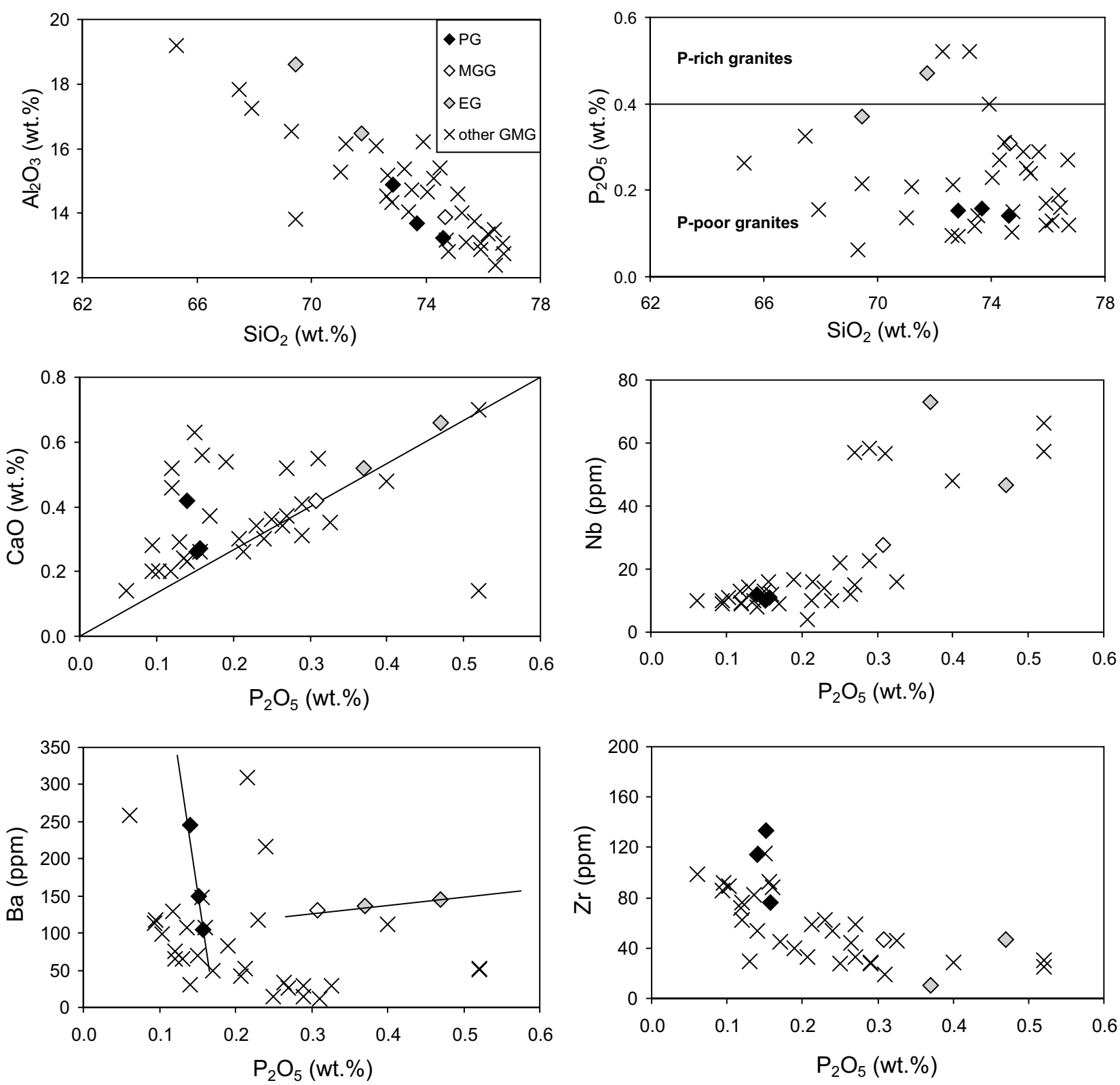

Fig. 5 Chemical variation diagrams for the porphyritic granites (PG) and evolved granites (MGG - medium-grained granite; EG - equigranular granite) from the Betliar area. The data are compared to other granites from the Gemeric Unit (other GMG) (unpublished data from Kubiš 2004).

K-feldspar phenocrysts from porphyritic granite show zoning in phosphorus concentrations. The $\mathrm{P}$ contents in the phenocryst cores are low $\left(0.03-0.09\right.$ wt. $\left.\% \mathrm{P}_{2} \mathrm{O}_{5}\right)$ but increase towards the rims $\left(0.13-0.25 \mathrm{wt} . \% \mathrm{P}_{2} \mathrm{O}_{5}\right)$. Barium abundances define a bell-shaped distribution which indicates origin by magmatic crystallization (Fig. 7). $\mathrm{K}$-feldspar from the medium-grained granite has very low P concentrations (below the detection limit; Tab. 2).

Albite domains in the perthites and individual albite crystals in the groundmass have very irregular phosphorus contents $\left(0.02-0.23\right.$ wt. $\left.\% \mathrm{P}_{2} \mathrm{O}_{5}\right)$. This is in contrast to the $\mathrm{P}_{2} \mathrm{O}_{5}$ contents in albites from the fine- and medium- grained granites, which are very low $\left(<0.09\right.$ wt. $\% \mathrm{P}_{2} \mathrm{O}_{5}$; Tab. 2).

Strongly altered plagioclase cores $\left(\mathrm{An}_{30}\right)$ in the porphyritic granite also show low $\mathrm{P}_{2} \mathrm{O}_{5}$ contents $(0.02-0.04$ wt. \%) as is true for albite rims ( $0.01 \mathrm{wt} \% \mathrm{P}_{2} \mathrm{O}_{5} ;$ Tab. 2) hosting numerous apatite inclusions.

\subsection{Micas}

Trioctahedral dark mica in porphyritic granite corresponds to annite with high molar $\mathrm{Fe} /(\mathrm{Fe}+\mathrm{Mg})$ ratio $(0.79-0.81$; Tab. 3). Annite crystals contain small inclusions of radio- 


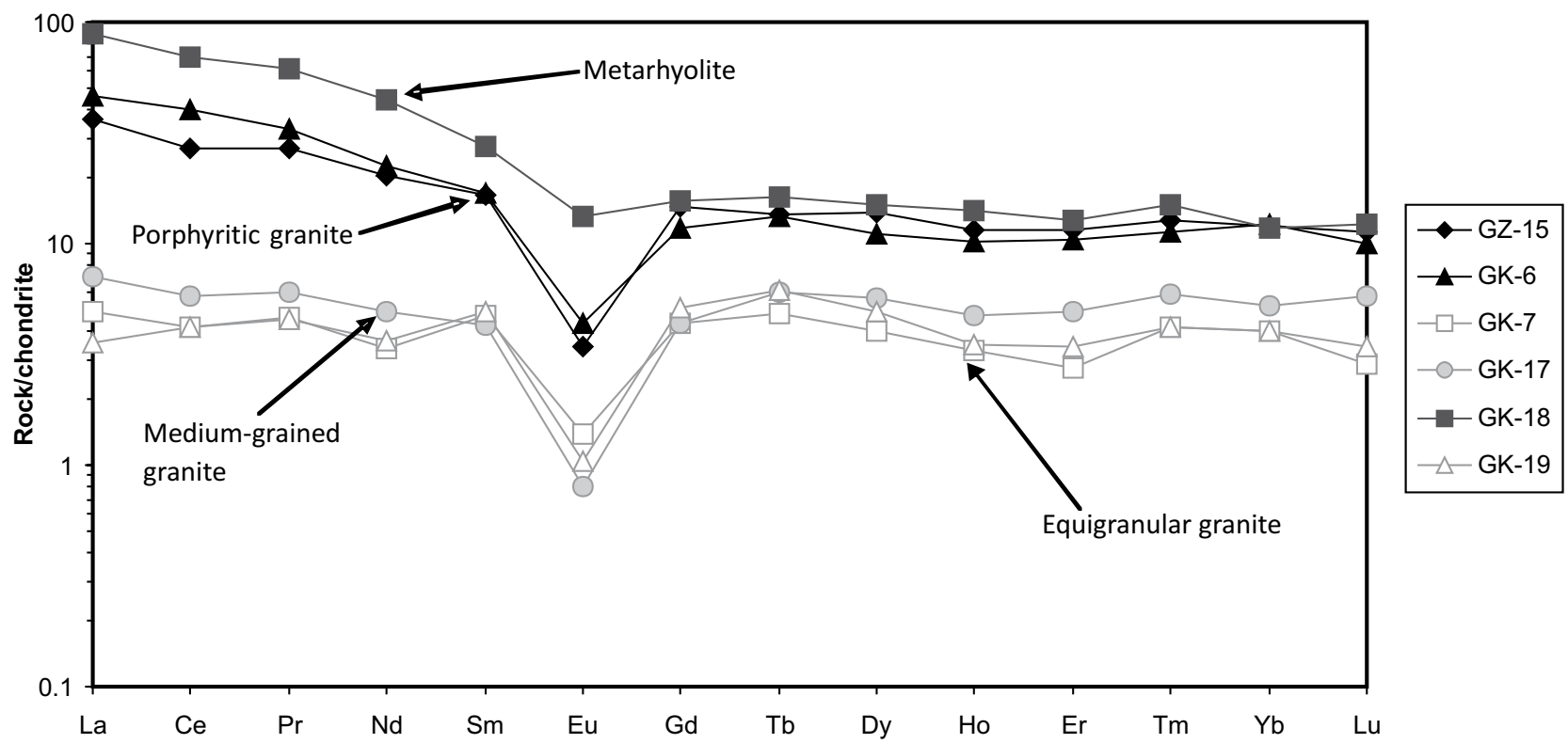

Fig. 6 REE chondrite-normalized patterns (Taylor and McLennan 1985) illustrating large differences between porphyritic granite and evolved granites from the Betliar granitic system.

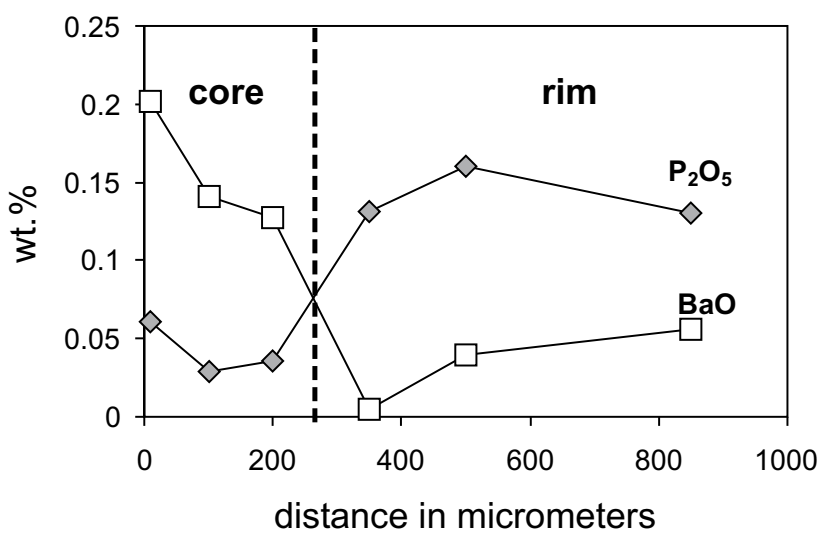

Fig. 7 Core-to-rim chemical variation in K-feldspar phenocryst from porphyritic granite (sample GK-6).

active minerals with pleochroic haloes. Fluorine concentrations are low (0.01-0.28 apfu). Annite occurs in three distinct forms: (i) an older "restitic" annite I found in central parts of (ii) annite II. These two phases can be easily distinguished by Ti concentrations whereby annite I is always depleted in Ti (Fig. 8); (iii) annite is also present in porphyritic granite as a breakdown product of an unknown euhedral mineral, probably cordierite. The pseudomorphs consist of tiny aggregates of annite III, muscovite and quartz in approximately equal proportions.

Dioctahedral white mica corresponds to muscovite of secondary origin or magnesian and ferroan "phengite" in all granite types (Tischendorf et al. 2007). Some of the white micas show low Fe concentrations (1.7 wt. \%),

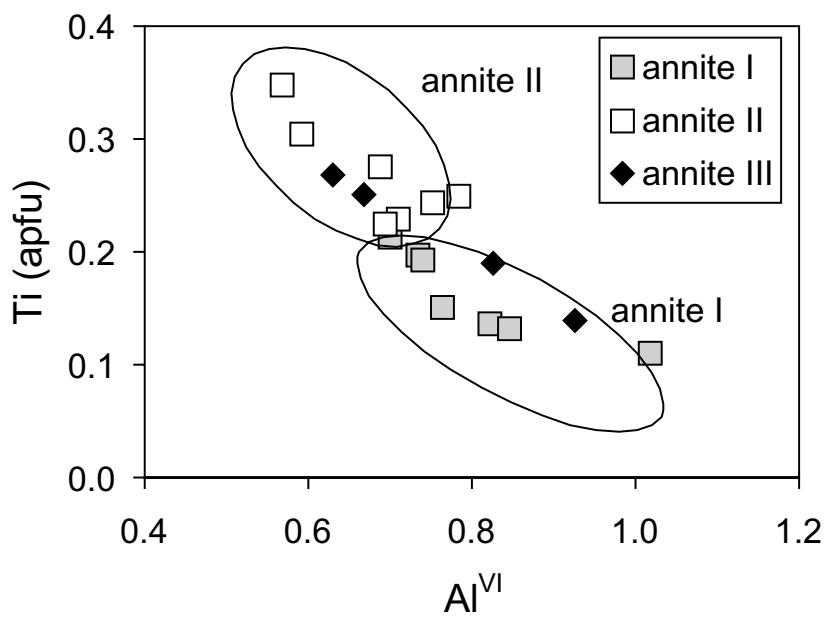

Fig. 8 Biotite (annite) in porphyritic granite has formed in two stages: Annite I is a relic whereas annite II crystallized in a deep-seated magma chamber. Annite III is a result of mineral breakdown (replacement of cordierite?).

but higher Fe concentrations ( 6.0 wt. \% $\mathrm{FeO}_{\text {тот }}$ ) are also encountered and the latter are probably unrelated to the Alpine metamorphic overprint (Tab. 3).

\section{Accessory minerals}

\subsection{Tourmaline}

Tourmaline is a widespread accessory mineral in all granite types and it forms four different types. A total of 
Tab. 2 Chemical composition of feldspars (in wt. \%)

\begin{tabular}{|c|c|c|c|c|c|c|c|c|}
\hline No. & 1 & 2 & 3 & 4 & 5 & 6 & 7 & 8 \\
\hline Sample & GK-6 & GK-6 & GK-6 & GK-6 & GK-6 & GK-7 & GK-17 & GK-17 \\
\hline Mineral & Kfs & Kfs & $\mathrm{Ab}$ & Kfs & Plg & $\mathrm{Ab}$ & Kfs & $\mathrm{Ab}$ \\
\hline Position & core & rim & matrix & matrix & restite & grain & grain & grain \\
\hline $\mathrm{SiO}_{2}$ & 64.22 & 63.71 & 66.46 & 64.86 & 61.91 & 68.02 & 64.74 & 68.76 \\
\hline $\mathrm{TiO}_{2}$ & 0.00 & 0.00 & 0.00 & 0.00 & 0.00 & 0.00 & 0.00 & 0.00 \\
\hline $\mathrm{Al}_{2} \mathrm{O}_{3}$ & 18.53 & 18.52 & 21.25 & 18.53 & 24.44 & 19.33 & 18.67 & 19.59 \\
\hline $\mathrm{FeO}$ & 0.01 & 0.01 & 0.01 & 0.00 & 0.04 & 0.01 & 0.00 & 0.00 \\
\hline $\mathrm{MnO}$ & 0.00 & 0.00 & 0.00 & 0.00 & 0.00 & 0.00 & 0.00 & 0.00 \\
\hline $\mathrm{MgO}$ & 0.00 & 0.00 & 0.00 & 0.00 & 0.00 & 0.00 & 0.00 & 0.03 \\
\hline $\mathrm{CaO}$ & 0.08 & 0.03 & 1.93 & 0.01 & 6.02 & 0.05 & 0.06 & 0.04 \\
\hline $\mathrm{BaO}$ & 0.04 & 0.20 & 0.00 & 0.06 & 0.01 & 0.00 & 0.08 & 0.01 \\
\hline $\mathrm{Na}_{2} \mathrm{O}$ & 0.25 & 0.38 & 10.73 & 0.41 & 8.20 & 11.87 & 0.37 & 10.98 \\
\hline $\mathrm{K}_{2} \mathrm{O}$ & 16.55 & 16.43 & 0.09 & 16.19 & 0.29 & 0.05 & 16.20 & 0.07 \\
\hline $\mathrm{P}_{2} \mathrm{O}_{5}$ & 0.16 & 0.06 & 0.30 & 0.25 & 0.06 & 0.09 & 0.08 & 0.00 \\
\hline Total & 99.83 & 99.33 & 100.77 & 100.31 & 100.97 & 99.42 & 100.20 & 99.48 \\
\hline \multicolumn{9}{|c|}{ Calculated on the basis of $8 \mathrm{O}$} \\
\hline $\mathrm{Si}$ & 2.979 & 2.976 & 2.895 & 2.986 & 2.725 & 2.990 & 2.986 & 3.007 \\
\hline $\mathrm{Ti}$ & 0.000 & 0.000 & 0.000 & 0.000 & 0.000 & 0.000 & 0.000 & 0.000 \\
\hline Al & 1.013 & 1.020 & 1.091 & 1.005 & 1.268 & 1.001 & 1.015 & 1.010 \\
\hline $\mathrm{Fe}$ & 0.000 & 0.000 & 0.001 & 0.000 & 0.002 & 0.000 & 0.000 & 0.000 \\
\hline $\mathrm{Mn}$ & 0.000 & 0.000 & 0.000 & 0.000 & 0.000 & 0.000 & 0.000 & 0.000 \\
\hline $\mathrm{Mg}$ & 0.000 & 0.000 & 0.000 & 0.000 & 0.000 & 0.000 & 0.000 & 0.002 \\
\hline $\mathrm{Ca}$ & 0.004 & 0.001 & 0.090 & 0.000 & 0.284 & 0.002 & 0.003 & 0.002 \\
\hline $\mathrm{Ba}$ & 0.001 & 0.004 & 0.000 & 0.001 & 0.000 & 0.000 & 0.001 & 0.000 \\
\hline $\mathrm{Na}$ & 0.022 & 0.034 & 0.906 & 0.036 & 0.700 & 1.012 & 0.033 & 0.931 \\
\hline $\mathrm{K}$ & 0.979 & 0.979 & 0.005 & 0.951 & 0.016 & 0.003 & 0.953 & 0.004 \\
\hline $\mathrm{P}$ & 0.006 & 0.002 & 0.011 & 0.010 & 0.002 & 0.003 & 0.003 & 0.000 \\
\hline $\mathrm{X}_{\mathrm{Ab}}$ & 0.022 & 0.033 & 0.905 & 0.037 & 0.700 & 0.995 & 0.033 & 0.994 \\
\hline$X_{\text {An }}$ & 0.004 & 0.001 & 0.090 & 0.000 & 0.284 & 0.002 & 0.003 & 0.002 \\
\hline $\mathrm{X}_{\mathrm{Or}}$ & 0.973 & 0.962 & 0.005 & 0.962 & 0.016 & 0.003 & 0.962 & 0.004 \\
\hline $\mathrm{X}_{\mathrm{Cs}}$ & 0.001 & 0.004 & 0.000 & 0.001 & 0.000 & 0.000 & 0.001 & 0.000 \\
\hline
\end{tabular}

three stages of tourmaline growth can be distinguished by combination of petrographic observations and mineral composition. The earliest type is represented by schorl with high molar $\mathrm{Fe} /(\mathrm{Fe}+\mathrm{Mg})$ ratio of $0.7-1.0$ and low $\mathrm{X}$-site vacancy $\left(\square^{\mathrm{X}}=0.1-0.5 \mathrm{apfu}\right.$; Tab. 4). This type is represented by euhedral, irregularly disseminated tourmalines that crystallized directly from a granitic magma.

The second type belongs to the interstitial nodular tourmaline formed near solidus or at early subsolidus temperatures. These tourmalines have molar $\mathrm{Fe} /(\mathrm{Fe}+\mathrm{Mg})$ ratios of $0.8-1.0$ and X-site vacancy, $\square^{\mathrm{X}}$ of $0.29-0.40 \mathrm{apfu}$.

The third type of tourmaline represented by schorl occurs in quartz-tourmaline veins cross-cutting the medium- and fine-grained equigranular granites. Tourmaline crystals from the veins show broad compositional varia-

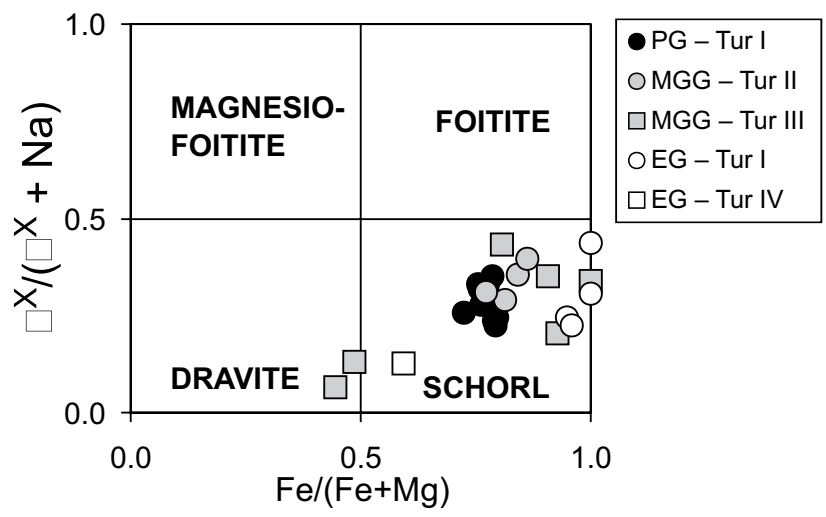

Fig. 9 Quadrilateral $\square^{\mathrm{X}} /\left(\square^{\mathrm{X}}+\mathrm{Na}\right)$ vs. Fe/(Fe $\left.+\mathrm{Mg}\right)$ diagram (atomic proportions) of tourmalines from Betliar area. 
Tab. 3 Chemical composition of micas (in wt. \%)

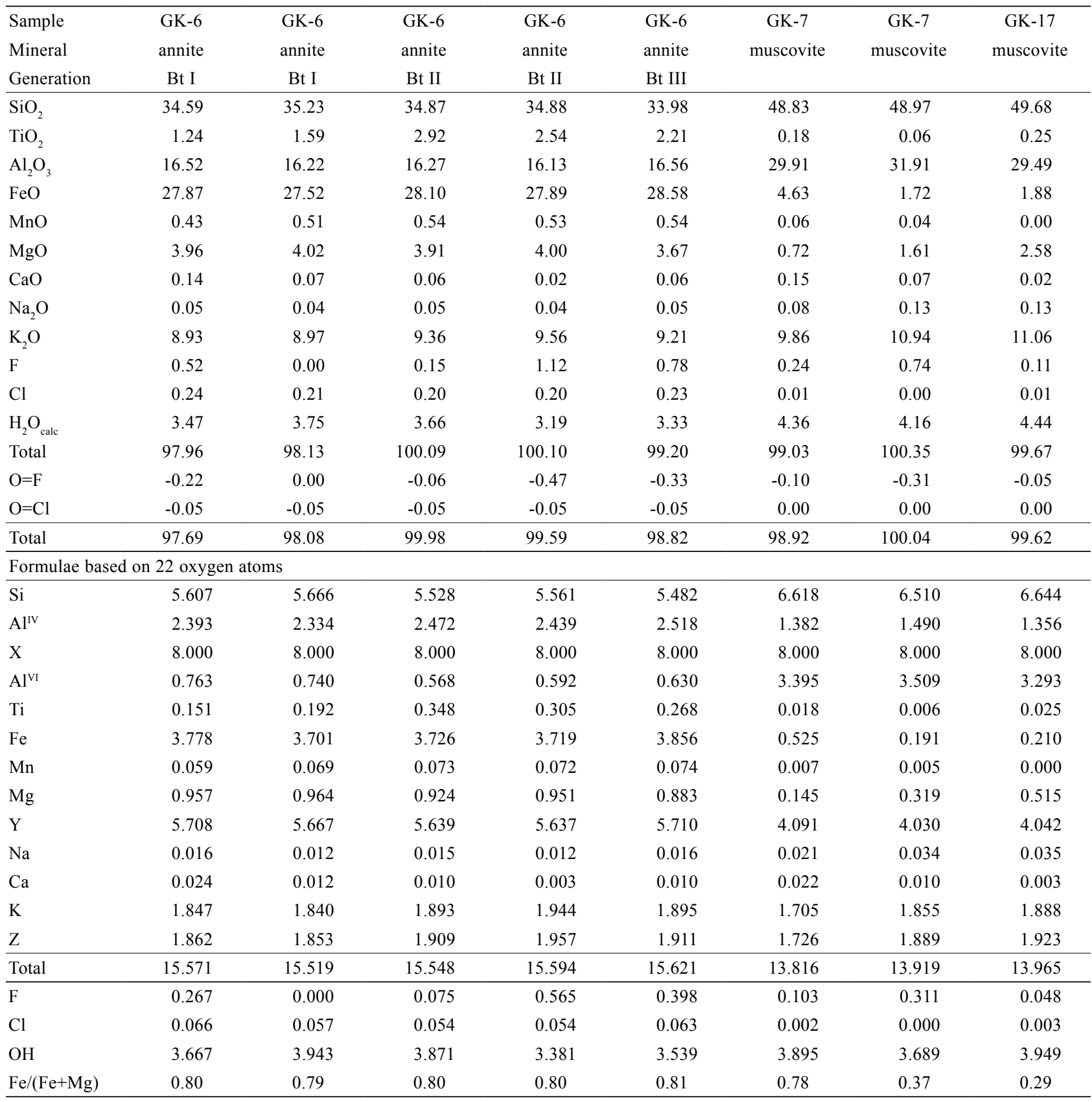

tion in schorl-dravite solid solution with molar $\mathrm{Fe} /(\mathrm{Fe}+$ $\mathrm{Mg})=0.44-0.93$ and $\mathrm{x}_{\square}=0.07-0.43$ apfu.

The fourth tourmaline type is represented by a latemagmatic or metamorphic schorl to dravite occurring in all granite types where it forms very thin veins or irregular grain clusters, filling cracks and fractures in preexisting tourmaline crystals. This tourmaline type shows lower molar $\mathrm{Fe} /(\mathrm{Fe}+\mathrm{Mg})$ ratio $(0.45-0.65$; Fig. 9) and its mineral chemistry is mainly controlled by substitutions represented by exchange vectors of $\mathrm{FeMg}_{-1}$ and $\mathrm{X}_{\square} \mathrm{PAl}^{\mathrm{X}} \mathrm{Na}_{-1}^{\mathrm{Y}}(\mathrm{Fe}, \mathrm{Mg})_{-1}$.

\subsection{Phosphates}

Apatite is present in two generations: the first type (primary magmatic apatite) is represented by large crystals $(\sim 150 \mu \mathrm{m}$ in size $)$ enriched in $\mathrm{Fe}$ and $\mathrm{Mn}(0.2-0.9$ wt. \% $\mathrm{FeO}, 3.0-4.2$ wt. \% $\mathrm{MnO}$ ) whereas the second type is found as inclusions in alkali feldspars, having probably formed by breakdown of feldspar with significant berlinite substitution. The second apatite type occurs as very small crystals $(\sim 3 \mu \mathrm{m}$ in size $)$ with low $\mathrm{Mn}$ and $\mathrm{Fe}$ contents. The highest amount of the small apatite inclu- 
Tab. 4 Chemical composition of tourmaline (in wt. \%)

\begin{tabular}{|c|c|c|c|c|c|c|c|c|}
\hline Sample & GK-6 & GK-6 & GK-17 & GK-17 & GK-17 & GK-17 & GK-7 & GK-7 \\
\hline Rock & $\begin{array}{l}\text { Porphyritic } \\
\text { granite }\end{array}$ & $\begin{array}{c}\text { Porphyritic } \\
\text { granite }\end{array}$ & $\begin{array}{l}\text { Medium-grained } \\
\text { granite }\end{array}$ & $\begin{array}{l}\text { Medium-grained } \\
\text { granite }\end{array}$ & $\begin{array}{l}\text { Medium-grained } \\
\text { granite }\end{array}$ & $\begin{array}{l}\text { Medium-grained } \\
\text { granite }\end{array}$ & $\begin{array}{l}\text { Equigranular } \\
\text { granite }\end{array}$ & $\begin{array}{l}\text { Equigranular } \\
\text { granite }\end{array}$ \\
\hline Type & Tur I & Tur I & Tur II & Tur II & Tur III & Tur III & Tur I & Tur IV \\
\hline $\mathrm{SiO}_{2}$ & 34.95 & 34.86 & 34.51 & 35.34 & 34.77 & 36.89 & 35.16 & 36.53 \\
\hline $\mathrm{TiO}_{2}$ & 0.80 & 0.45 & 0.66 & 0.77 & 0.40 & 0.34 & 0.49 & 0.09 \\
\hline $\mathrm{B}_{2} \mathrm{O}_{3} *$ & 10.38 & 10.47 & 10.46 & 10.44 & 10.30 & 10.58 & 10.15 & 10.46 \\
\hline $\mathrm{Al}_{2} \mathrm{O}_{3}$ & 33.26 & 35.19 & 35.22 & 34.37 & 34.11 & 31.12 & 31.19 & 30.76 \\
\hline $\mathrm{Cr}_{2} \mathrm{O}_{3}$ & 0.00 & 0.00 & 0.00 & 0.00 & 0.00 & 0.00 & 0.00 & 0.00 \\
\hline $\mathrm{FeO}$ & 12.40 & 11.41 & 12.37 & 12.93 & 15.20 & 9.94 & 16.51 & 12.22 \\
\hline $\mathrm{MnO}$ & 0.15 & 0.15 & 0.15 & 0.15 & 0.00 & 0.02 & 0.11 & 0.08 \\
\hline $\mathrm{MgO}$ & 2.56 & 2.40 & 1.59 & 1.15 & 0.00 & 5.92 & 0.52 & 4.70 \\
\hline $\mathrm{CaO}$ & 0.35 & 0.33 & 0.25 & 0.16 & 0.08 & 0.04 & 0.01 & 0.02 \\
\hline $\mathrm{Na}_{2} \mathrm{O}$ & 2.12 & 1.95 & 2.08 & 1.80 & 1.98 & 2.69 & 2.24 & 2.68 \\
\hline $\mathrm{K}_{2} \mathrm{O}$ & 0.05 & 0.08 & 0.05 & 0.03 & 0.04 & 0.04 & 0.05 & 0.04 \\
\hline $\mathrm{H}_{2} \mathrm{O}^{*}$ & 3.38 & 3.30 & 3.61 & 3.44 & 3.55 & 3.65 & 3.08 & 3.21 \\
\hline $\mathrm{F}$ & 0.54 & 0.67 & 0.00 & 0.35 & 0.00 & 0.00 & 0.88 & 0.84 \\
\hline $\mathrm{Cl}$ & 0.00 & 0.00 & 0.00 & 0.00 & 0.00 & 0.00 & 0.02 & 0.00 \\
\hline $\mathrm{O}=\mathrm{F}$ & -0.23 & -0.28 & 0.00 & -0.15 & 0.00 & 0.00 & -0.37 & -0.35 \\
\hline $\mathrm{O}=\mathrm{Cl}$ & 0.00 & 0.00 & 0.00 & 0.00 & 0.00 & 0.00 & 0.00 & 0.00 \\
\hline Total & 100.30 & 100.61 & 100.95 & 100.78 & 100.43 & 101.23 & 100.04 & 101.28 \\
\hline \multicolumn{9}{|c|}{ Formulae based on 31 oxygen atoms } \\
\hline $\mathrm{Si}^{4+}$ & 5.850 & 5.786 & 5.735 & 5.882 & 5.867 & 6.060 & 6.02 & 6.067 \\
\hline $\mathrm{Al} \mathrm{T}$ & 0.150 & 0.214 & 0.265 & 0.118 & 0.133 & -0.060 & -0.020 & -0.067 \\
\hline$\Sigma \mathrm{T}$ & 6.000 & 6.000 & 6.000 & 6.000 & 6.000 & 6.000 & 6.000 & 6.000 \\
\hline $\mathrm{B}^{3+}$ & 3.000 & 3.000 & 3.000 & 3.000 & 3.000 & 3.000 & 3.000 & 3.000 \\
\hline $\mathrm{Al} \mathrm{Z}$ & 6.000 & 6.000 & 6.000 & 6.000 & 6.000 & 6.000 & 6.000 & 6.000 \\
\hline $\mathrm{Ti}^{4+}$ & 0.101 & 0.056 & 0.082 & 0.096 & 0.051 & 0.042 & 0.063 & 0.011 \\
\hline Al Y & 0.411 & 0.670 & 0.633 & 0.625 & 0.651 & 0.085 & 0.314 & 0.088 \\
\hline $\mathrm{Cr}^{3+}$ & 0.000 & 0.000 & 0.000 & 0.000 & 0.000 & 0.000 & 0.000 & 0.000 \\
\hline $\mathrm{Fe}^{2+}$ & 1.685 & 1.584 & 1.719 & 1.800 & 2.145 & 1.366 & 2.364 & 1.697 \\
\hline $\mathrm{Mn}^{2+}$ & 0.021 & 0.021 & 0.021 & 0.021 & 0.000 & 0.003 & 0.016 & 0.011 \\
\hline $\mathrm{Mg}^{2+}$ & 0.639 & 0.505 & 0.394 & 0.285 & 0.000 & 1.450 & 0.133 & 1.164 \\
\hline$\Sigma Y$ & 2.857 & 2.836 & 2.849 & 2.827 & 2.847 & 2.946 & 2.890 & 2.971 \\
\hline Vac. Y & 0.143 & 0.164 & 0.151 & 0.173 & 0.153 & 0.054 & 0.110 & 0.029 \\
\hline Al total & 6.561 & 6.884 & 6.898 & 6.743 & 6.784 & 6.025 & 6.294 & 6.021 \\
\hline $\mathrm{Ca}^{2+}$ & 0.063 & 0.059 & 0.045 & 0.029 & 0.014 & 0.007 & 0.002 & 0.004 \\
\hline $\mathrm{Na}^{+}$ & 0.688 & 0.628 & 0.67 & 0.581 & 0.648 & 0.857 & 0.744 & 0.863 \\
\hline $\mathrm{K}+$ & 0.011 & 0.017 & 0.011 & 0.006 & 0.009 & 0.008 & 0.011 & 0.008 \\
\hline$\sum \mathrm{X}$ & 0.762 & 0.704 & 0.726 & 0.616 & 0.671 & 0.872 & 0.757 & 0.875 \\
\hline Vac. X & 0.238 & 0.296 & 0.274 & 0.384 & 0.329 & 0.128 & 0.243 & 0.125 \\
\hline $\mathrm{OH} \mathrm{V}$ & 3.000 & 3.000 & 3.000 & 3.000 & 3.000 & 3.000 & 3.000 & 3.000 \\
\hline $\mathrm{OH}$ total & 3.714 & 3.648 & 4.000 & 3.816 & 4.000 & 4.000 & 3.518 & 3.559 \\
\hline $\mathrm{OH} \mathrm{W}$ & 0.714 & 0.648 & 1.000 & 0.816 & 1.000 & 1.000 & 0.518 & 0.559 \\
\hline $\mathrm{F}^{-}$ & 0.286 & 0.352 & 0.000 & 0.184 & 0.000 & 0.000 & 0.477 & 0.441 \\
\hline $\mathrm{Cl}^{-}$ & 0.000 & 0.000 & 0.000 & 0.000 & 0.000 & 0.000 & 0.006 & 0.000 \\
\hline Sum W & 1.000 & 1.000 & 1.000 & 1.000 & 1.000 & 1.000 & 1.001 & 1.000 \\
\hline $\mathrm{O}^{2-}$ & 30.714 & 30.648 & 31.000 & 30.816 & 31.000 & 31.000 & 30.518 & 30.559 \\
\hline CATSUM & 18.618 & 18.538 & 18.574 & 18.444 & 18.518 & 18.818 & 18.647 & 18.847 \\
\hline $\mathrm{Fe} /(\mathrm{Fe}+\mathrm{Mg})$ & 0.73 & 0.76 & 0.81 & 0.86 & 1.00 & 0.49 & 0.95 & 0.59 \\
\hline
\end{tabular}


sions was found in greisenized granites or greisens where phosphorus was mobilized during feldspar breakdown (GK-19). The newly-formed apatite is mostly located in white mica aggregates and is often accompanied by $\mathrm{Nb}-$ Ta-W phases (Fig. 4d).

Monazite-(Ce) with 3.3-9.5 wt. \% $\mathrm{ThO}_{2}$ and $0.1-0.25$ wt. $\% \mathrm{UO}_{2}$ is the main host of light rare earth elements in the porphyritic granite. It is locally slightly enriched in cheralite end-member ( 4-9 mol. \%). High cheralite contents in monazite (28-46 mol. \%) have been found in fine-grained granite in association with wolframite. There are $26.7-32.7$ wt. $\% \mathrm{ThO}_{2}$ and $0.9-4.1$ wt. $\% \mathrm{UO}_{2}$. Electron microprobe dating of the monazite-(Ce) from porphyritic granite revealed Permian to Early Triassic age. A total of 13 analyses were obtained from homogenous crystals, with a weighted mean of $247 \pm 13 \mathrm{Ma}$

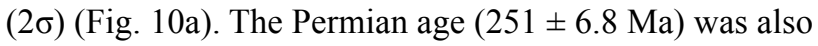
obtained by electron microprobe dating of the monazite from the fine-grained equigranular granite (Fig. 10b).
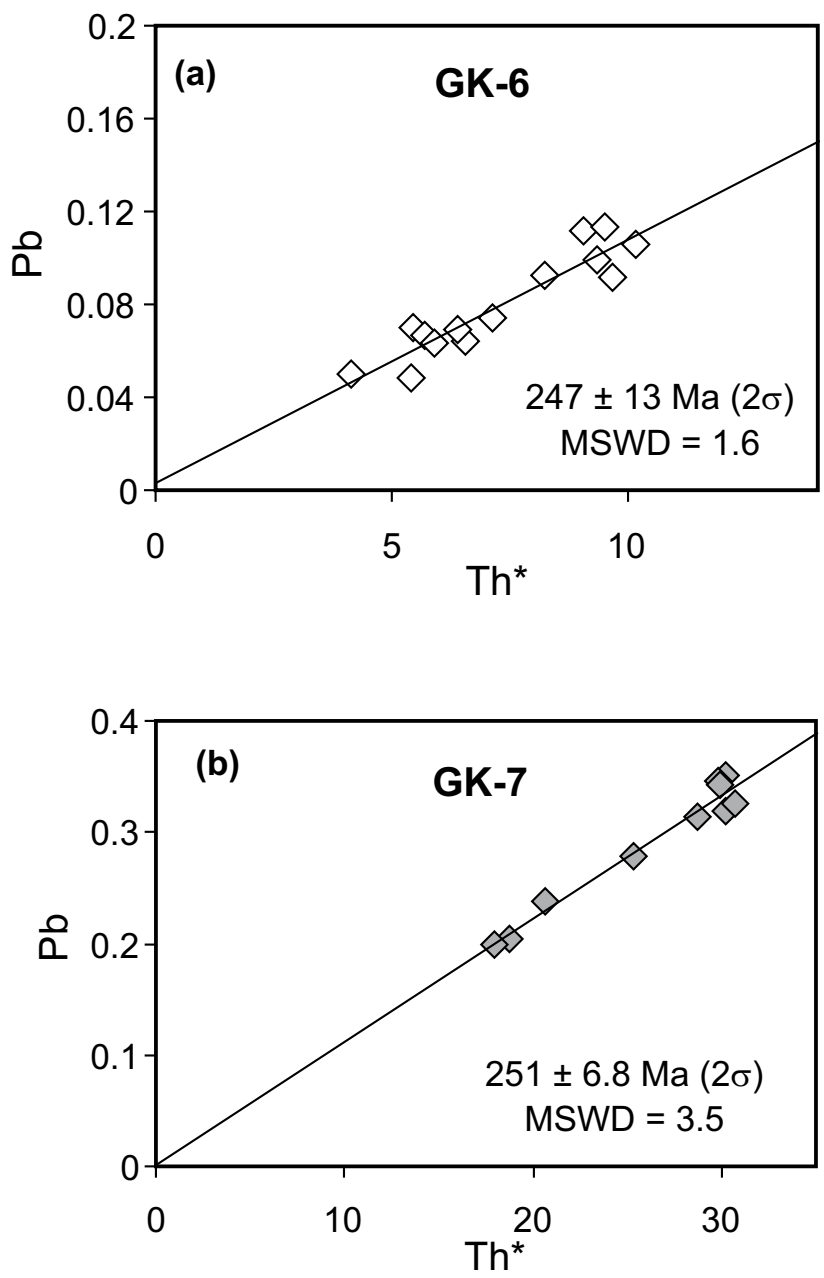

Fig. 10 Isochron diagrams (Konečný et al. 2004) illustrating the electron microprobe data for monazite from the porphyritic granite (GK-6) and the equigranular fine-grained granite (GK-7).

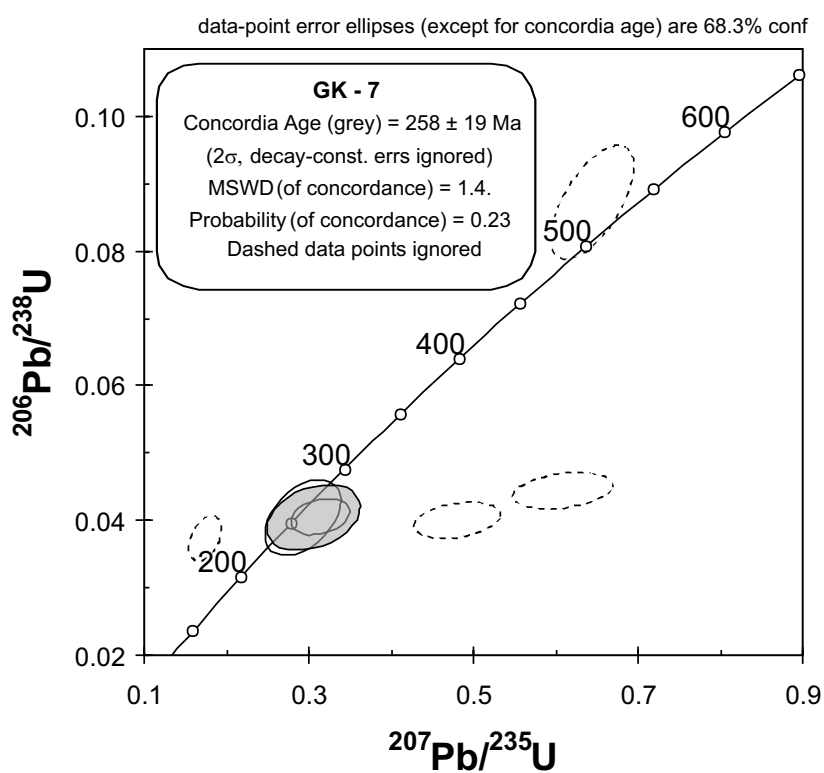

Fig. 11 Concordia plot for LA ICP-MS U-Pb zircon data from the finegrained equigranular granite GK-7.

\subsection{Zircon}

Zircon population from the porphyritic granite is dominated by morphological subtypes S7, S8, S9, S10, less frequently S4, S3 and S6 (Pupin 1980). A second zircon generation consists of mainly metamict, low-temperature crystals with prevalence of G1 and P1 subtypes. The typological mean point for the sample GK-6 corresponds to I.A. $=480$ and I.T $=364$. Zircon in the porphyritic granite is mainly accompanied by xenotime-(Y) with irregular uranium distribution.

Fine-grained equigranular granite contains ubiquitous zircons with cores and magmatic oscillatory zoning in their outer parts. Resorbed grains were observed frequently. Zircon nucleation centres display oscillatory zoning and are commonly oval in shape. Typical morphometric subtypes in the sample GK-7 correspond to S8, S7, S12, S3 and S4 subtypes, whereas younger zircon generation belongs to the G1 subtype. The typological mean point is characterized by I.A $=524$ and I.T $=342$. In some other cases, cores show a primary crystal shape, with sector or irregular oscillatory zoning.

The LA-ICP-MS U-Pb dating of 6 zircon crystals from the fine-grained equigranular granite GK-7 yielded three concordant and four discordant ages (Fig. 11). The oldest discordant age of $538 \pm 33 \mathrm{Ma}$ (grain GK-7-7) might be interpreted as a result of $\mathrm{Pb}$ inheritance in a regular core as verified by sector zoning in cathodoluminescence images. The crystallization age of this sample is defined by grains GK-7-16 and GK-7-22 (Fig. 11, Tab. 5). The concordant grains yielded an emplacement date of 258 
Tab. 5 LA ICP-MS isotope data from zircon grains from the fine-grained equigranular granite (sample GK-7).

\begin{tabular}{|c|c|c|c|c|c|c|c|c|c|}
\hline \multirow{2}{*}{$\begin{array}{l}\text { Sample } \\
\text { Spot }\end{array}$} & \multicolumn{5}{|c|}{ Measured ratios } & \multicolumn{4}{|c|}{ Ages (Ma) } \\
\hline & ${ }^{207} \mathrm{~Pb} /{ }^{235} \mathrm{U}$ & $7 / 5$ err & ${ }^{206} \mathrm{~Pb} /{ }^{238} \mathrm{U}$ & $6 / 8$ err & Rho & ${ }^{207} \mathrm{~Pb} /{ }^{235} \mathrm{U}$ & $1 \sigma$ & ${ }^{206} \mathrm{~Pb} /{ }^{238} \mathrm{U}$ & $1 \sigma$ \\
\hline GK-7-8 & 0.6104 & 0.0400 & 0.0442 & 0.0018 & 0.31 & 483.8 & 25.2 & 278.8 & 11.1 \\
\hline GK-7-7 & 0.6459 & 0.0332 & 0.0870 & 0.0056 & 0.63 & 505.9 & 20.5 & 537.5 & 33.4 \\
\hline GK-7-12 & 0.1756 & 0.0129 & 0.0372 & 0.0023 & 0.42 & 164.3 & 11.1 & 235.2 & 14.1 \\
\hline GK-7-22 & 0.2941 & 0.0303 & 0.0402 & 0.0036 & 0.44 & 261.8 & 23.8 & 253.8 & 22.6 \\
\hline GK-7-16 & 0.3153 & 0.0240 & 0.0402 & 0.0018 & 0.29 & 278.3 & 18.6 & 254.0 & 11.2 \\
\hline GK-7-14 & 0.4819 & 0.0353 & 0.0398 & 0.0017 & 0.30 & 399.4 & 24.2 & 251.4 & 10.8 \\
\hline
\end{tabular}

err - error of measurement, 1 sigma; Rho - error correlation

$\pm 19 \mathrm{Ma}$ for the fine-grained equigranular granite. The discordant data from grains GK-7-12 and GK-7-14 plot close to the accepted crystallization age (Tab. 5).

\section{Discussion}

\subsection{Granite evolution and origin of the composite granite system}

The Betliar granites record a prolonged magmatic evolution. The composite nature of the granite suite is interpreted as having resulted from a multistage granite emplacement of magmas with distinct chemical composition. Geochemistry of the porphyritic granites differs from the more evolved one represented by equigranular or medium-, and fine-grained Betliar granites. In comparison to porphyritic granite, the evolved equigranular granites are significantly enriched in rare metals $(\mathrm{Nb}, \mathrm{Ta}, \mathrm{W})$ and exhibit a stronger alteration resulting in the formation of greisens. They most likely intruded at a shallow crustal level as a sill-like body, subsequently followed by emplacement of distinct magma batches forming the Betliar porphyritic granite (granite porphyry).

Remarkable differences in HFSE and REE concentrations between the porphyritic and evolved equigranular medium- and fine-grained granites are characteristic of a protracted magmatic differentiation (e.g. Dostal and Chatterjee 1995; Ramirez and Menedez 1999; Haapala and Lukkari 2005; Antunes et al. 2008). Fractional crystallization could have also been responsible for a decrease in $\mathrm{Ti}, \mathrm{Fe}$ and $\mathrm{Co}$, and an enrichment in incompatible elements ( $\mathrm{Ta}, \mathrm{Nb}, \mathrm{Rb}, \mathrm{Cs}$ etc.) observed from the most primitive porphyritic to the most evolved rare-metal enriched granites. The decrease in Zr, REE, Y and Th abundances in the granite complex is consistent with fractionation of accessory silicates and phosphates. The elements $\mathrm{Ba}$ and $\mathrm{P}$ in $\mathrm{K}$-feldspar are sensitive to igneous differentiation (Mehnert and Büsch 1981; Long and Luth 1986; Cox et al. 1996) and define the evolutionary path during igneous evolution (Larsen 2002). The elemental variation in $\mathrm{P}$ and $\mathrm{Ba}$ between megacryst cores and rim compositions in porphyritic granite is an evidence for protracted crystallization in the deeper seated melt batch of the porphyritic granite (Fig. 7).

The evolution of the composite granitic system was characterized by early solidification of the emplaced magma from the reservoir margins inwards (formation of the carapace) and its subsequent rupture that allowed emplacement of more evolved, volatile-rich melts derived from the underlying parental magma chamber (Fig. 12). A similar scenario has been proposed for the intrusive sequences in the Cornubian ore field, SW England (Jackson et al. 1989) or the evolution of the Mole Granite in Australia (Audétat et al. 2000; Schaltegger et al. 2005). Finally, the ascent path was used by another pulse of silicate magma now represented by the Betliar porphyritic granite. The zircon saturation geothermometry (Watson and Harrison 1983) applied to porphyritic granites yielded temperatures of $740-800{ }^{\circ} \mathrm{C}$, which may be interpreted as the temperature of magmatic zircon saturation in the parental magma. On the other hand, lower zircon saturation temperatures $\left(685-745{ }^{\circ} \mathrm{C}\right)$ determined for the fine- to medium-grained granites are comparable with those from highly evolved, P- and F-rich magmas, for instance from the Kymi stock, Finland (e.g. Haapala and Lukkari 2005).

The evolved granites yielded an age of $258 \pm 19 \mathrm{Ma}$ (Fig. 11) and a similar SHRIMP zircon age was also reported from an adjacent Súl'ová granite body $(257.7 \pm$ $4 \mathrm{Ma}$; Radvanec et al. 2009). Conventional single-grain zircon dating of the porphyritic Betliar granite yielded a slightly younger age (246 \pm 5 Ma; Poller et al. 2002). A similar relationship was revealed by monazite, which yielded a slightly older age for the evolved granite and a younger age for the porphyritic granite (Fig. 10). However, these ages can be considered the same within the error. On the other hand, relatively high $\mathrm{U}-\mathrm{Pb}$ concordant zircon age of $277 \mathrm{Ma}$ for the porphyritic granite recently determined using the SHRIMP method opens some questions regarding the granite evolution (Radvanec et al. 2009). In this sense the age difference between evolution 


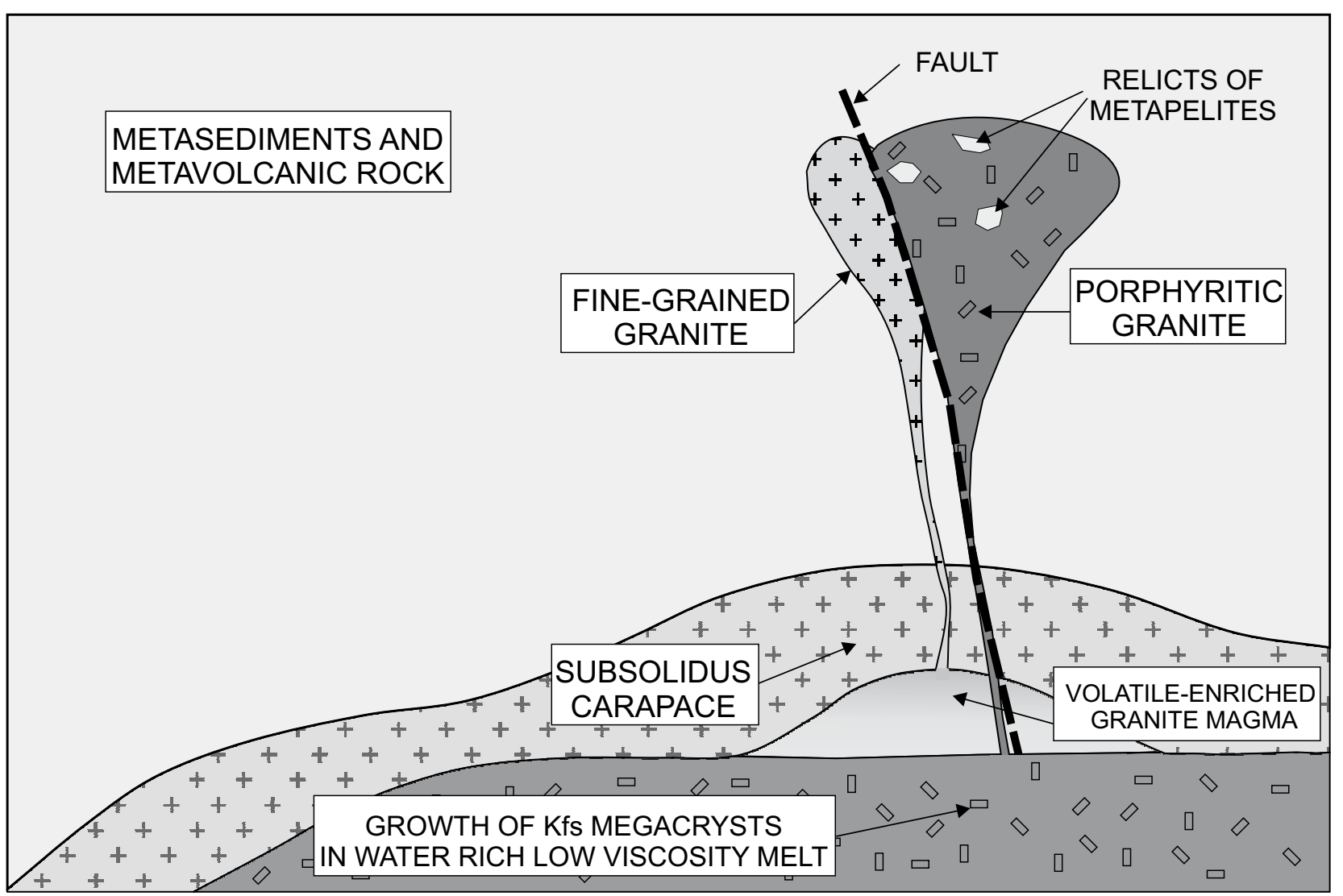

Fig. 12 Geological sketch illustrating the postulated successive intrusion events that are thought to have formed the composite Betliar Granite Massif.

of equigranular and fine-grained granites is hypothetical, supported solely by the observed geological relationships and granite evolutionary trend.

\subsection{Tourmaline as result of fractionation and high volatile flux}

Tourmaline in the Betliar granitic system formed in several stages but its precipitation in the nodular form remains the most peculiar one (Fig. 2c). Tourmaline nodules are known from a number of localities worldwide and their formation was suggested to be related to magmatic crystallization and penetration of hydrothermal fluids (e.g., Samson and Sinclair 1992; Buriánek and Novák 2007; Trumbull et al. 2008). Tourmaline nodules at Moslavačka Gora in Croatia (Balen and Broska in press) have been interpreted as indicating decompression and ascent of fluids during shallow emplacement. The supersaturation in aqueous fluids in the magma may result in formation of vapour bubbles and their migration through the granite body. Subsequently, rupture of roof rocks and release of residual B-bearing volatiles could have led also to the formation of hydrothermal quartztourmaline veins (Fig. 2d).

Enrichment in $\mathrm{F}, \mathrm{B}$ and $\mathrm{H}_{2} \mathrm{O}$ in the Betliar granitic magmas can be explained by fractional crystallization of initially enriched parental melts (Thomas et al. 2005). During solidification, a reaction between biotite and B-bearing silicate melt was proposed to give rise to tourmaline (Shearer et al. 1987). The stability of tourmaline is further enhanced by low Ti abundances, which stabilize tourmaline over biotite (Nabelek et al. 1992). The commonly observed association of tourmalinization (boron metasomatism) in nature is consistent with the preferential partitioning of boron into aqueous vapour of magmatic-hydrothermal systems (Schatz et al. 2004).

\subsection{Alteration of equigranular granites}

Equigranular granites that crystallized from volatilerich melts have undergone strong subsolidus alteration (greisenization). The greisenization of the fine-grained granites and formation of the $\mathrm{Sn}-\mathrm{W}-\mathrm{Nb}-\mathrm{Ta}$ vein mineralization with abundant tourmaline resulted from a high 
flux of hydrothermal fluids. Such a process was discussed previously in the Hnilec area (Kubiš and Broska 2005).

Remarkably, greisens are enriched in phosphorus (Fig. 4d) and we propose that secondary apatite might have originated from decomposition of albite that contained berlinite end-member, $\mathrm{AlPO}_{4}$ (London et al. 1990; London 1992, 1998). High P contents in alkali feldspars were reported from the evolved peraluminous granites worldwide (London et al. 1990; Bea et al. 1992; Pichavant et al. 1992; Frýda and Breiter 1995; Breiter et al. 1997, 1999, 2002; Breiter 2001). The presence of $P$ in alkali feldspars in the Hnilec granites was already described by Broska et al. $(2001,2002)$.

\section{Concluding remarks}

Field, petrological and geochemical data indicate a composite nature of the Betliar granite. We suggest the following multistage petrogenetic scenario: (i) intrusion of porphyritic granite intrusion followed after the emplacement of earlier magma batches now preserved as medium- to fine-grained equigranular granites, (ii) magmas were taping an evolved upper (?) portion of a deep-seated magma chamber, (iii) the growth of alkali feldspar megacrysts commenced in a deep-seated magmatic chamber whereas the medium-grained matrix solidified after emplacement at shallow crustal level, and (iv) the equigranular granites were subsequently altered to greisens.

Acknowledgements. This work was supported by the Slovak Research and Development Agency under the contract No. APVT-13-604. The authors are indebted to Jan Košler for access to the zircon dating facility (LA-MS ICP) housed at Charles University (Prague, Czech Republic), to Patrik Konečný for the monazite datings and to Vratislav Hurai for his comments. The authors are also grateful to Carlos Villaseca, Pavel Uher and David Dolejš for their reviews that helped to substantially improve an early version of the manuscript.

\section{References}

Antunes IMHR, Neiva AMR, Silva MMVG, Corfu F (2008) Geochemistry of S-type granitic rocks from the reversely zoned Castelo Branco pluton (central Portugal). Lithos 103: 445-465

Audétat A, Günther D, HeinRich CA (2000) Magmatichydrothermal evolution in a fractionating granite: a microchemical study of the $\mathrm{Sn}-\mathrm{W}-\mathrm{F}-$ mineralized Mole Granite (Australia). Geochim Cosmochim Acta 64: 3373-3393
Bajaník Š, Ivanička J, Mello J, Pristaš J, Reichwalder P, Snopko L, VozÁr J, VozÁrová A (1984) Geological map of the Slovenské Rudohorie Mts. - eastern part 1: 50000. Dionýz Štúr Institute of Geology, Bratislava

Balen D, BRoska I (2010) Tourmaline nodules - products of devolatilization within the final evolutionary stage of granitic melt? J Geol Soc, London (in press)

Bea F, Fershtater GB, Corretgé LG (1992) The geochemistry of phosphorus in granite rocks and the effects of aluminium. Lithos 29: 43-56

Breiter K (2001) Phosphorus- and fluorine-rich granite system at Podlesí. In: Breiter K (ed.) Phosphorus- and Fluorine-rich Fractionated Granites: Abstracts, Excursion guide, Programme. Czech Geological Survey, Prague, pp 52-78

Breiter K, Frýda J, Seltmann R, Thomas R (1997) Mineralogical evidence for two magmatic stages in the evolution of an extremely fractionated P-rich rare-metal granite: the Podlesí stock, Krušné Hory, Czech Republic. J Petrol 38: 1723-1739

Breiter K, Förster HJ, Seltmann R (1999) Variscan silicic magmatism and related tin-tungsten mineralization in the Erzgebirge-Slavkovský les metallogenic province. Miner Depos 34: 505-521

Breiter K, Frýda J, Leichmann J (2002) Phosphorus and rubidium in alkali feldspars: case studies and possible genetic interpretation. Bull Czech Geol Surv 77: 93-104

BRoska I, Uher P (2001) Whole-rock chemistry and genetic typology of the West-Carpathian Variscan granites. Geol Carpath 52: 79-90

Broska I, DiAnIŠKa I, Kubiš M, Uher P (2001) Spiš-Gemer granites (Slovakia): geochemistry, age and origin. In: Breiter K (ed) Phosphorus- and Fluorine-rich Fractionated Granites: Abstracts, Excursion guide, Programme. Czech Geological Survey, Prague, pp 4-5

Broska I, Kubiš M, Williams CT, KoneČnÝ P (2002) The compositions of rock-forming and accessory minerals from the Gemeric granites (Hnilec area, Gemeric Superunit, Western Carpathians). Bull Czech Geol Surv 77: 147-155

Buriánek D, NovÁk M (2007) Compositional evolution and substitutions in disseminated and nodular tourmaline from leucogranite granites: examples from Bohemian Massif, Czech Republic. Lithos 95: 145-164

Cox RA, Dempster TY, Bell BR, Rogers G (1996) Crystallization of the Shap Granite: evidence from zoned K-feldspar megacrysts. J Geol Soc, London 153: 625-635

Dostal J, Chatterjee AK (1995) Origin of topaz-bearing and related peraluminous granites of the Late Devonian Davis Lake pluton, Nova Scotia, Canada: crystal versus fluid fractionation. Chem Geol 123: 67-88

Finger F, Broska I (1999) The Gemeric S-type granites in southeastern Slovakia: Late Paleozoic or Alpine intrusion? Evidence from electron-microprobe dating of monazite. Schweiz Mineral Petrogr Mitt 79: 439-443 
FRÝDA J, BREITER K (1995) Alkali feldspars as a main phosphorus reservoirs in rare-metal granites: three examples from the Bohemian Massif (Czech Republic). Terra Nova 7: 315-320

Grecula P (ed.) (1995) Mineral Deposits of the Slovak Ore Mountains. Volume 1. Mineralia Slovaca Corporation, Bratislava, pp 1-834

HaApala I, LukKari S (2005) Petrological and geochemical evolution of the Kymi stock, a topaz granite cupola within the Wiborg rapakivi batholith, Finland. Lithos 80: $347-362$

Jackson NJ, Willis-Richards J, Manning DAC, Sams MS (1989) Evolution of the Cornubian ore field, southwest England: Part II. Mineral deposits and ore-forming processes. Econ Geol 84: 1101-1133

KamenicKÝ J, KamenicKÝ L (1955) The Gemeric granite and ore mineralization of the Spiš-Gemer Mts. Geol Práce, Zbor 41: 5-73 (in Slovak)

KANTOR J $(1957){ }^{40} \mathrm{Ar} /{ }^{40} \mathrm{~K}$ method of absolute age determination of rocks and their application to the Betliar granite. Geol Práce, Zbor 11: 188-200 (in Slovak)

KoneČnÝ P, Siman P, HolickÝ I, Janák M, Kollárová V (2004) Method of monazite dating by means of the electron microprobe. Miner Slov 36: 225-235 (in Slovak with English abstract)

Kovách A, Svingor E, Grecula P (1986) Rb-Sr isotopic ages of granitoids from the Spišsko-Gemerské Rudohorie Mts. Miner Slov 18: 1-14

KuBIŠ M (2004) Origin and evolution of Spiš-Gemeric granites. Unpublished $\mathrm{PhD}$. thesis, Geological Institute, Academy of Sciences, Bratislava, pp 1-153 (in Slovak with English abstract)

Kubiš M, Broska I (2005) The role of boron and fluorine in evolved granitic rock systems (on the example of the Hnilec area, Western Carpathians). Geol Carpath 56: 193-204

LARSEN RB (2002) The distribution of rare-earth elements in $\mathrm{K}$-feldspar as an indicator of petrogenetic processes in granitic pegmatites: examples from two pegmatite fields in southern Norway. Canad Mineral 40: 137-151

London D (1992) Phosphorus in S-type magmas: the $\mathrm{P}_{2} \mathrm{O}_{5}$ content of feldspars from peraluminous granites, pegmatites and rhyolites. Amer Miner 77: 126-145

London D (1998) Phosphorus-rich peraluminous granites. Acta Univ Carol, Geol 42: 64-68

LONDON D, ČERnÝ P, LOOMIS JL, PAN JJ (1990) Phosphorus in alkali feldspars of rare-element granitic pegmatites. Canad Mineral 28: 771-786

LoNG PE, LuTH WC (1986) Origin of K-feldspar megacrysts in granitic rocks: implication of a partitioning model for barium. Amer Miner 71: 367-375

LuDWIG KR (2001) Isoplot/Ex ver. 2.49. A geochronological toolkit for Microsoft Excel. User manual. Berkeley Geochronological Centre Special Publications 1a: pp 1-56
Malachovský P, UheR P, ĎuĎA R (2000) Nb-W minerals in the Dlhá Dolina rare-element granite, the Spiš-Gemer Ore Mountains. Natura Carpatica 41: 7-14 (in Slovak)

MeHNERT KR, BüsCh W (1981) The Ba content of K-feldspar megacrysts in granites: a criterion for their formation. Neu Jb Mineral, Abh 140: 221-252

Nabelek P, Russ-Nabelek C, Denison JR (1992) The generation and crystallization of Proterozoic Harney Peak leucogranite, Black Hills, South Dakota, USA: petrologic and geochemical constrains. Contrib Mineral Petrol 110: 173-191

ONČÁKovÁ P (1954) Petrography and petrochemistry of Gemeric granites. Geol Práce, Zoš 39: 3-53 (in Slovak)

Pichavant M, Montel JM, Richard LR (1992) Apatite solubility in peraluminous liquids: experimental data and extension of the Harrison-Watson model. Geochim Cosmochim Acta 56: 3855-3861

Plašsienka D, Grecula P, Putiš M, Hovorka D, Kováč M (1997) Evolution and structure of the Western Carpathians. In: Grecula P, Hovorka D, Putiš M (eds) Geological Evolution of the Western Carpathians. Miner Slov - Monograph, Bratislava, pp 1-24

Poller U, Uher P, Broska I, Plašienka D, Janák M (2002) First Permian-Early Triassic zircon ages for tin-bearing granites from the Gemeric unit (Western Carpathians, Slovakia): connection to the post-collisional extension of the Variscan orogen and S-type granite magmatism. Terra Nova 14: 41-48

PupIN JP (1980) Zircon and granite petrology. Contrib Mineral Petrol 73: 207-220

Radvanec M, Konečný P, Ondrejka M, Putiš M, Uher P, NÉMETH Z (2009) The Gemeric granites as an indicator of the crustal extension above the Late-Variscan subduction zone and during the Early Alpine riftogenesis (Western Carpathians): an interpretation from the monazite and zircon ages dated by CHIME and SHRIMP methods. Miner Slov 41: 381-394 (in Slovak with English summary).

Ramirez JA, Menendez LG (1999) A geochemical study of two peraluminous granites from south-central Iberia: the Nisa-Alburquerque and Jalama batholiths. Mineral Mag 63: 85-104

RozložNík L, SLAvKovskÝ J, JACKo S (1980) Final report to project II-4-5/1.6: Relations of mineralized structures to tectogenesis of Western Carpathians. Unpublished Manuscript, archive of Department of Geology and Mineralogy, Technical University, Košice, pp 1-144 (in Slovak)

SAMSON IM, SincLaIR WD (1992) Magmatic hydrothermal fluids and the origin of quartz-tourmaline orbicles in the Seagull Batholith, Yukon Territory. Canad Mineral 30: 937-954

Schaltegger U, Pettke T, Audétar A, Reusser E, Heinrich CHA (2005) Magmatic-to-hydrothermal crystallization in the W-Sn mineralized Mole Granite (NSW Australia). 
Part I: crystallization of zircon and REE-phosphates over three million years - a geochemical and $\mathrm{U}-\mathrm{Pb}$ geochronological study. Chem Geol 220: 215-235

Schatz OJ, Dolejš D, Stix J, Williams-Jones AE, Layne GD (2004) Partitioning of boron among melt, brine and vapor in the system haplogranite- $\mathrm{H}_{2} \mathrm{O}-\mathrm{NaCl}$ at $800{ }^{\circ} \mathrm{C}$ and $100 \mathrm{MPa}$. Chem Geol 210: 135-147

Shearer CK, Papike JJ, Laul JC (1987) Mineralogical and chemical evolution of a rare-element granite-pegmatite system: Harney Peak Granite, Black Hills, South Dakota. Geochim Cosmochim Acta 51: 473-486

TaYlor SR, McLennan SM (1985) The Continental Crust: Its Composition and Evolution. Blackwell, Oxford, pp $1-312$

Thomas R, Förster HJ, Rickers K, Webster JD (2005) Formation of extremely F-rich hydrous melt fractions and hydrothermal fluids during differentiation of highly evolved tin-granite magmas: a melt/fluid-inclusion study. Contrib Mineral Petrol 148: 582-601

Tischendorf G, Förster HJ, Gottesmann B, Rieder M (2007) True and brittle micas: composition and solidsolution series. Mineral Mag 71: 285-620
Trumbull RB, Krienitz MS, Gottesmann B, Wiedenbeck M (2008) Chemical and boron-isotope variations in tourmalines from a S-type granite and its source rocks: the Erongo granite and tourmalinites in the Damara Belt, Namibia. Contrib Mineral Petrol 155: 1-18

Uher P, Broska I (1996) Post-orogenic Permian granitic rocks in the Western Carpathian-Pannonian area: geochemistry, mineralogy and evolution. Geol Carpath 47: 311-321

Uher P, Broska I, DianišKa I, Kubiš M, Malachovský P (2001) Tourmalines and $\mathrm{Nb}-\mathrm{Ta}-\mathrm{W}$ minerals in fractionated P- and F-rich granites: an example from the Spiš-Gemer granites, Eastern Slovakia. In: BREITER K (ed.) Phosphorus- and Fluorine-rich Fractionated Granites: Abstracts, Excursion guide, Programme. Czech Geological Survey, Prague, pp 32-33

VARČEK C (1959) Metallogenesis of the Spiš-Gemer Mts. Acta Geol Geogr Univ Comen, Geol 2: 123-138 (in Slovak)

WATSON EB, Harrison TM (1983) Zircon saturation revisited: temperature and composition effects in a variety of crustal magma types. Earth Planet Sci Lett 64: $295-304$ 